This document is confidential and is proprietary to the American Chemical Society and its authors. Do not copy or disclose without written permission. If you have received this item in error, notify the sender and delete all copies.

\title{
Hippocampal proteomic and metabonomic abnormalities in neurotransmission, oxidative stress and apoptotic pathways in a chronic phencyclidine rat model
}

\begin{tabular}{|r|l|}
\hline Journal: & Journal of Proteome Research \\
\hline Manuscript ID: & pr-2015-00105f.R1 \\
\hline Manuscript Type: & Article \\
\hline Date Submitted by the Author: & $29-$ May-2015 \\
\hline Complete List of Authors: & $\begin{array}{l}\text { Wesseling, Hendrik; University of Cambridge, Institute of Biotechnology } \\
\text { Want, Elizabeth; Imperial College London, Division of Surgery, Oncology, } \\
\text { Reproductive Biology and Anaesthetics } \\
\text { Guest, Paul; University of Cambridge, Institute of Biotechnology } \\
\text { Rahmoune, Hassan; University of Cambridge, Institute of Biotechnology } \\
\text { Holmes, Elaine; Imperial College, Biomedical Sciences } \\
\text { Bahn, Sabine; University of Cambridge, }\end{array}$ \\
\hline
\end{tabular}

SCHOLARONE

Manuscripts 


\title{
Hippocampal proteomic and metabonomic abnormalities in neurotransmission, oxidative stress and apoptotic pathways in a chronic phencyclidine rat model
}

\author{
Hendrik Wesseling ${ }^{1}$, Elizabeth J. Want ${ }^{2}$, Paul C. Guest ${ }^{1}$, Hassan Rahmoune ${ }^{1}$, Elaine \\ Holmes $^{2}$, Sabine Bahn* ${ }^{1,3}$ \\ ${ }^{I}$ Department of Chemical Engineering and Biotechnology, University of Cambridge, Cambridge CB2 1QT, UK \\ ${ }^{2}$ Section of Biomolecular Medicine, Division of Computational and Systems Medicine, Department of Surgery \\ and Cancer, Faculty of Medicine, Imperial College, London, SW7 2AZ, UK \\ ${ }^{3}$ Department of Neuroscience, Erasmus Medical Center, 3000 CA Rotterdam, The Netherlands \\ *corresponding author: Professor Sabine Bahn, Department of Chemical Engineering and Biotechnology, \\ University of Cambridge, Cambridge, Tennis Court Road, CB2 1QT, UK Tel: +44 (0) 1223334151, e-mail: \\ sb209@cam.ac.uk (e-mail: sb209@cam.ac.uk) \\ HW (M.Sc.): hw350@cam.ac.uk \\ EJW (PhD): e.want@imperial.ac.uk \\ PCG (PhD): pg110@cam.ac.uk \\ HR (PhD): $\quad$ hr288@cam.ac.uk \\ EH (Prof.): ｅlaine.holmes@imperial.ac.uk \\ SB (Prof.): $\quad$ sb209@cam.ac.uk
}

Keywords: chronic phencyclidine (PCP) rat model, schizophrenia, LC-MS ${ }^{\mathrm{E}}$, SRM, Metabonomics, multiplex immunoassay, proteomics 
ABSTRACT

Schizophrenia is a neuropsychiatric disorder affecting $1 \%$ of the world's population. Due to a broad range of symptoms and disease heterogeneity, current therapeutic approaches to treat schizophrenia fail to address all symptomatic manifestations of the disease. Therefore, disease models that reproduce core pathological features of schizophrenia are needed for the elucidation of pathological disease mechanisms. Here, we employ a comprehensive global label-free liquid chromatography-mass spectrometry proteomic (LC-MS ${ }^{\mathrm{E}}$ ) and metabonomic (LC-MS) profiling analysis combined with targeted proteomics (selected reaction monitoring and multiplex-immunoassay) of serum and brain tissues to investigate a chronic phencyclidine (PCP) rat model, in which glutamatergic hypofunction is induced through noncompetitive NMDAR-receptor antagonism. Using multiplex immunoassay, we identified alterations in the levels of several cytokines (IL-5, IL-2, IL-1ß) and fibroblast-growth factor2. Extensive proteomic and metabonomic brain tissue profiling revealed a more prominent effect of chronic PCP treatment on both the hippocampal proteome and metabonome compared to the frontal cortex. Bioinformatic pathway analysis confirmed prominent abnormalities in NMDA-receptor associated pathways in both brain regions, as well as alterations in other neurotransmitter systems such as kainate, AMPA and GABAergic signalling in the hippocampus and in proteins associated with neurodegeneration. We further identified abundance changes in the level of the superoxide dismutase enzyme (SODC) in both the frontal cortex and hippocampus, which indicate alterations in oxidative stress and substantiates the apoptotic pathway alterations. The present study could lead to an increased understanding of how perturbed glutamate receptor signalling affects other relevant biological pathways in schizophrenia and therefore support drug discovery efforts for improved treatment of patients suffering from this debilitating psychiatric disorder. 


\section{Introduction}

The potent N-methyl-D-aspartate (NMDA) antagonist phencyclidine (PCP) is one of the most extensively studied animal models of psychiatric disorders. PCP is a psychotomimetic (i.e. able to elicit positive symptoms), ${ }^{1}$ which is also able to induce negative ${ }^{1 \mathrm{a}, 2}$ and cognitive ${ }^{3}$ symptoms which are core features of schizophrenia and other psychiatric disorders, in both humans and rodents. ${ }^{4}$ In addition, it can exacerbate these symptoms in schizophrenia patients. ${ }^{5}$ Thus, studies of PCP feature prominently in pharmaceutical drug discovery efforts since most current treatments of schizophrenia are predominately tailored to treat positive symptoms, while negative and cognitive symptoms tend to be more resistant to antipsychotic treatment. Mechanistically, PCP shows an affinity to a variety of receptors [sigma, dopamine $\mathrm{D}(2)$ and 5-HT(2) receptors $\left.{ }^{6}\right]$ but principally acts at the NMDA receptor (NMDAR), where it binds with high affinity to a specific site within the pore of the ion channel, leading to a NMDAR hypofunction. However, PCP is also an antagonist for the dopamine (D2) receptor, inducing abnormalities of dopaminergic transmission in different brain regions in primates ${ }^{7}$ and rodents. ${ }^{8}$ Thereby, PCP models both glutamate and dopamine dysfunction, which represent the key neurotransmitter systems implicated in the pathophysiology of schizophrenia. ${ }^{9}$ However, other neurotransmitter systems, such as serotonin/norepinephrine, ${ }^{8 \mathrm{a}, 10}$ gamma-aminobutyric acid (GABA), ${ }^{9,11}$ acetylcholine $^{12}$ and opioid pathways are also affected by PCP treatment, albeit to a lesser extent. ${ }^{13}$ Rodent PCP models are currently among the most commonly used in schizophrenia drug discovery. Previous studies have characterized these models mainly at the behavioural level, with the finding of shared behavioural abnormalities of hyperlocomotion, stereotypy, ${ }^{14}$ decreased voluntary sucrose consumption, ${ }^{15}$ impaired information processing with cognitive functions of memory ${ }^{16}$ and attention and impaired social interaction. ${ }^{14,17}$ The behavioural readouts are thought to correspond to the positive, negative and cognitive symptoms as seen 
in human schizophrenia. Fewer studies have been performed at the physiological and molecular level, although these have implicated abnormalities of neurotransmitter release and levels, ${ }^{7 a}, 8 \mathrm{a}, 16,18$ dendritic branching, and dendritic spine number, synaptic loss, ${ }^{19}$ along with hypofrontality. ${ }^{20}$ To date, the molecular mechanisms by which PCP exerts diverse neurochemical, behavioural and clinical effects are still a matter of debate. The first proteomic studies of an acute PCP rat model revealed abnormalities in protein phosphorylation patterns in the frontal corte ${ }^{21}$ and energy metabolism and signal transduction in the hippocampus. ${ }^{22}$ Less has been done to investigate chronic PCP (cPCP) effects in the brain, although it has been noted that repeated substance abuse of PCP by humans induces more persistent schizophrenia symptomatology, including psychosis, hallucinations, delusions, formal thought disorder and cognitive dysfunction and social withdrawal. ${ }^{1 \mathrm{a}, 23}$ One extensive proteomic and metabonomic study which investigated the molecular effects in the frontal cortex of a cPCP rat model, led to the identification of subtle abnormalities in proteins involved in calcium signalling and energy metabolism. ${ }^{24}$ Here, we attempt to gain further insights into the effects of cPCP treatment using a combination of metabonomic and proteomic profiling of rat brain tissue. Since only subtle molecular changes have been found in the frontal cortex of $\mathrm{cPCP}$ treated rats, ${ }^{24}$ this study now analyses hippocampal tissue from cPCP treated rats to investigate how this brain region is affected, particularly considering its role in cognition and memory, social behaviour and the (negative) symptom domains. The molecular characterisation will help to improve the understanding of pathophysiological mechanisms associated with psychosis and schizophrenia and support drug discovery and development efforts. 


\section{Material and Methods}

\section{Animals}

Adult male Sprague-Dawley rats (Charles River, Margate, UK) were housed in groups of four under standard laboratory conditions with food (Harlan UK, Bicester, UK) and water available ad libitum. All experiments were conducted during the light cycle and were in full compliance with the Home Office Guidance (UK Animals Scientific Procedures Act 1986) and ethical policies of the Home Office. After a 10-day adaptation period, rats were given a daily subcutaneous dose of vehicle ( $0.9 \%$ sterile saline) or PCP hydrochloride $(5 \mathrm{mg} / \mathrm{kg})$ for 15 consecutive days. All animals were killed by decapitation $30 \mathrm{~min}$ after the last injection and brain tissues dissected. Behavioural readouts were recorded as described and PCP injection induced the standard increase in locomotor activity and stereotypic movement. ${ }^{24}$

\section{Serum profiling}

Serum preparation, multiplex immunoassays and statistical analysis were performed as described previously. ${ }^{22,25}$ Blood was collected from rats into S-Monovette $7.5 \mathrm{~mL}$ serum tubes (Sarstedt; Numbrecht, Germany) and left for $1.5 \mathrm{~h}$ at room temperature for clotting. The blood was centrifuged at $300 \mathrm{~g}$ for $15 \mathrm{~min}$ at $4^{\circ} \mathrm{C}$. Resulting supernatants (serum samples) were stored in Low Binding Eppendorf tubes (Hamburg, Germany) at $-80^{\circ} \mathrm{C}$. Serum samples were analyzed using the RodentMAP, Rat MetabolicMAP and Rat KidneyMAP platforms comprising multiplexed immunoassays of 89 analytes in a Clinical Laboratory Improved Amendments (CLIA)-certified laboratory at Myriad-RBM (Austin, TX, USA). ${ }^{25}$ Immunoassays were calibrated using duplicate standard curves for each analyte and raw intensity measurements converted to protein concentrations using proprietary software. Multiplexed calibrators (eight levels per analyte) and controls (three levels per analyte) were used to monitor key performance parameters, such as lower limit of quantification, precision, cross-reactivity, linearity, spike-recovery, dynamic range, matrix interference, freeze-thaw 
stability and short-term sample stability (http://www.myriadrbm.com/technology/dataquality/). Data analyses were performed using the statistical software package $\mathrm{R}$ (http://www.r-project.org) and the levels of analytes were determined. Analyses were conducted under blinded conditions with respect to sample identities and samples were analyzed in random order to avoid any sequential biases. For data analysis, all missing values, zeros and negative values were replaced by the half of the minimum positive value, assuming this to be the detection limit. Analytes with more than $30 \%$ missing values were removed. 66 analytes remained for relative quantification. Furthermore, approximately $10 \%$ of the data were filtered out based on relative standard deviation (RSD). ${ }^{26}$ Row-wise normalization to each median reading was employed to adjust for differences among samples and data were log-transformed and pareto-scaled (mean-centered and divided by the square root of standard deviation of each variable) to make features more comparable. Significance Analysis of Microarray (SAM) was performed using the Siggenes R package. ${ }^{27}$ SAM is a well-established statistical method for identification of differentially expressed genes in microarray data analysis and is frequently employed for analysis of high-throughput Omicsdatasets. It is designed to address the false discovery rate (FDR) when running multiple tests and high-dimensional data. SAM assigns a significance score to each variable based on change relative to the standard deviation of repeated measurements. For a variable with scores greater than an adjustable threshold, its relative difference is compared to the distribution estimated by random permutation of the class labels. For each threshold, a certain proportion of the variables in the permutation set will be identified as significantly different by chance. This proportion is used to calculate the FDR. ${ }^{28}$ 


\section{Global metabolic profiling}

Metabonomic profiling was performed as described previously. ${ }^{29}$ In brief, approximately $10 \mathrm{mg}$ frontal cortex and 30-50mg hippocampus tissues were weighed out into $2 \mathrm{~mL}$ bead beater tubes and homogenized with $1.45 \mathrm{~mL}$ of pre-chilled methanol/water $(1: 1)$ and $100 \mu \mathrm{L}$ of 1-mm zirconium beads, using a Precellys bead beater. Homogenisation (6,5000 Hz speed) cycles were 40 s, followed by cooling on dry ice, and a further 40 s homogenisation and cooling on dry ice. The mixtures were then centrifuged at $10,000 \mathrm{~g}$ for $10 \mathrm{~min}$ at $4^{\circ} \mathrm{C}$.

Supernatants (aqueous extracts) were collected and transferred to clean Eppendorf tubes. Aqueous extracts were dried in a vacuum concentrator (Savant) for at least $180 \mathrm{~min}$ at $45^{\circ} \mathrm{C}$. Extracts were resuspended in $120 \mu \mathrm{L}$ of methanol/water $(1: 1)$, followed by brief vortexing and sonication, and transferred into 96-well plates for analysis. Quality control (QC) samples were prepared by combining an aliquot $(10 \mu \mathrm{L})$ from each study sample to produce a representative sample - this was used for column conditioning and data quality assessment as described by Want et al. ${ }^{29}$

UPLC-MS analysis was performed using a Waters XEVO G2 Q-TOF mass spectrometer coupled online to an Acquity UPLC-MS system (Waters Corporation, Milford, MA). Separation was performed at $0.4 \mathrm{~mL} / \mathrm{min}$ and $50^{\circ} \mathrm{C}$, using a $2.1 \times 100 \mathrm{~mm}(1.7 \mu \mathrm{m}) \mathrm{HSS}$ T3 Acquity column. The injection volume was $5 \mu \mathrm{L}$ and the sample temperature was $4^{\circ} \mathrm{C}$. The mobile phases were $0.1 \%(\mathrm{vol} / \mathrm{vol})$ formic acid in water (A) and $0.1 \%(\mathrm{vol} / \mathrm{vol})$ formic acid in methanol (B). The gradient was (99.9\% A for $2 \mathrm{~min}$, to $75 \% \mathrm{~A}$ in $4 \mathrm{~min}$; to $20 \% \mathrm{~A}$ in $6 \mathrm{~min}$, to $10 \% \mathrm{~A}$ in $2 \mathrm{~min}$, to $0.1 \% \mathrm{~A}$ in $7 \mathrm{~min}, 0.1 \% \mathrm{~A}$ for $2 \mathrm{~min}$, to $99.9 \% \mathrm{~A}$ in $4 \mathrm{~min}$ ). Acquisition was performed in both positive ion mode $(1.0 \mathrm{kV}$ ESI +$)$ and negative ion mode (1.0kV ESI-). Source conditions were: source temperature: $120^{\circ} \mathrm{C}$, desolvation temperature: $350^{\circ} \mathrm{C}$, cone gas flow: $25 \mathrm{~L} / \mathrm{h}$, desolvation gas flow: $900 \mathrm{~L} / \mathrm{h}$. QC samples were injected ten times at the 
start of the analytical batch in order to condition the column, then after every ten samples throughout the run to assess instrument stability.

Data were processed using the freeware $\mathrm{XCMS}^{30}$ using standard parameters. The output consisted of a matrix of metabolite feature $\mathrm{m} / \mathrm{z}$, retention time and intensity (peak area) values. These "metabolite feature" tables were imported into SIMCA-P for multivariate analysis (e.g. PCA) to check data quality and sample outliers. All missing and zero values $(0.02 \%$ of the data $)$ were replaced by the half of the minimum positive value found within the data. The assumption of this approach is that most of the missing values are caused by low abundance metabolites. Since zero values may cause problems for data normalization (i.e. $\log$ ), they were replaced with this value. Data were filtered to identify and remove variables that were unlikely to be of use when modelling the data. $10 \%$ of data points showing little variance across experimental conditions were filtered based on relative standard deviation. ${ }^{31}$ This filtering procedure is highly recommended for chemometric data, which often contains a large amount of noise. Row-wise normalization to sample median was employed to adjust for differences among samples and data was log transformed and pareto-scaled (mean-centered and divided by the square root of standard deviation of each variable) to make features more comparable. $P$-Values were determined using SAM and corrected to control for multiple hypothesis testing. ${ }^{28}$ Ratios were calculated for each molecule as the mean intensity values of cPCP-treated rats divided by those of controls.

\section{Proteomic Sample Preparation}

Total lysis sample preparation was performed as previously described using a fractionation buffer containing 7M urea, 2M thiourea, $4 \%$ CHAPS, $2 \%$ ASB14, 70mM dithiotreitol (DTT) and protease inhibitor at a 5:1 (v/w) ratio. ${ }^{25,32}$ Samples were sonicated (10s, 2 cycles) and vortexed at $4^{\circ} \mathrm{C}$ for $30 \mathrm{~min}$. Samples were then centrifuged at $17,000 \mathrm{~g}$ at $4{ }^{\circ} \mathrm{C}$. Protein 
concentrations of the lysates were determined using a Bradford assay (Bio-Rad; Hemel Hempstead, UK). Approximately $100 \mu \mathrm{g}$ sample was precipitated using acetone. After dissolving the precipitate in $50 \mathrm{mM}$ ammonium bicarbonate, reduction of sulfhydryl groups were performed with $5 \mathrm{mM}$ DTT at $60^{\circ} \mathrm{C}$ for $30 \mathrm{~min}$ and alkylation was carried out using $10 \mathrm{mM}$ iodacetamide at $37^{\circ} \mathrm{C}$ for $30 \mathrm{~min}$ in the dark and proteins were subsequently digested using trypsin at a $1: 50(\mathrm{w} / \mathrm{v})$ ratio for $17 \mathrm{~h}$ at $37^{\circ} \mathrm{C}$. Reactions were stopped by addition of $8.8 \mathrm{M} \mathrm{HCl}$ in a 1:60 (w/w) ratio. Quality control $(\mathrm{QC})$ samples were prepared to monitor machine and preparation performance. For this, an equal amount of each sample was pooled into one sample after the sonication step and then split into multiple aliquots. Each QC sample underwent all experimental steps in parallel with the test samples.

\section{Label-free $\mathrm{LC}-\mathrm{MS}^{\mathrm{E}}$ analysis of frontal cortex and hippocampus tissue}

Individual digested brain tissue samples were analyzed in duplicates $(0.6 \mu \mathrm{g}$ protein per duplicate) using a splitless nanoACQUITY -ultra-performance liquid chromatography (UPLC) (10 kpsi nanoAcquity; Waters Corporation, Milford, MA) for reverse-phase chromatographic peptide separation coupled online to a Waters Q-TOF Premier mass

spectrometer. Data were acquired in expression mode $\left(\mathrm{MS}^{\mathrm{E}}\right)$. The system was comprised of a C18 trapping column $(180 \mu \mathrm{m} \times 20 \mathrm{~mm} ; 5 \mu \mathrm{m}$ particle size $)$ and a $\mathrm{C} 18 \mathrm{BEH}$ nanocolumn $(75$ $\mu \mathrm{m} \times 200 \mathrm{~mm} ; 1.7 \mathrm{~mm}$ particle size). The buffers were as follows: (A) $\mathrm{H} 2 \mathrm{O}+0.1 \%$ formic acid and (B) acetonitrile $+0.1 \%$ formic acid. Initial buffer concentrations were 3\% B (97\% A) followed by $3-30 \% \mathrm{~B}(90 \mathrm{~min}), 30-90 \% \mathrm{~B}(25 \mathrm{~min}), 90-97 \% \mathrm{~B}(5 \mathrm{~min})$, constant $97 \% \mathrm{~B}$ (10 min), and $97-3 \%$ B (1 min). Every $30 \mathrm{~s}$ approximately $500 \mathrm{fmol} / \mu \mathrm{L}$ Glu Fibrinopeptide B was infused via a lock spray for external lock mass correction. The mass spectrometer was operated in $\mathrm{V}$ mode, and analyses were carried out using positive nanoESI ion mode. Collision energy was $5 \mathrm{eV}$ for low-energy scans and ramped from 17 to $40 \mathrm{eV}$ for high- 
energy scans (cycle time $1.3 \mathrm{~s}$ ). The low collision energy (MS) generated information about intact precursor ions, and the high collision energy $\left(\mathrm{MS}^{\mathrm{E}}\right)$ provides information about the corresponding peptide fragments. Fragment ions are matched to corresponding precursor peptide ions based on retention time, mass accuracy and other physiochemical properties. ${ }^{33}$ Data processing was done by using the ProteinLynx Global Server (PLGS) v.2.4 (Waters Corporation; Milford, MA, U.S.A.) and Rosetta Elucidator v.3.3 (Rosetta Biosoftware; Seattle, WA, U.S.A.) for time and mass/charge alignment of mass spectrometer data as described previously. Aligned peaks were extracted and abundance measurements obtained by integration of time, $\mathrm{m} / \mathrm{z}$ and intensity volumes, with normalization to the total ion current. The procedure, quality assessment and data processing were performed as described previously. ${ }^{22}$ PLGS2.4 using the Swiss-Prot rodent reference proteome (Uniprot release March 2013) was used for protein identification searches. In order to control the false discovery rate (FDR), data were searched against a decoy database, which was the randomised version of the database mentioned above to conserve amino acid frequencies. The FDR was set at the default maximum rate of $4 \%$, as applied before. ${ }^{34}$ The search parameters were (i) enzyme $=$ trypsin, (ii) fixed modification $=$ carbamidomethylation of cysteines, (iii) variable modifications = oxidation of methionine and phosphorylation at serine, threonine or tyrosine residues, (iv) initial mass accuracy tolerances $=10 \mathrm{ppm}$ for precursor ions and $20 \mathrm{ppm}$ for product ions, and (v) one missed cleavage allowed. In addition, the following criteria were used for protein identification: (i) $\geq 3$ fragment ions per peptide, (ii) $\geq 7$ fragment ions per protein, and (iii) $\geq 1$ peptide per protein. Raw data and PLGS search results were imported into the Rosetta Elucidator software (build 3.3.0.1.SP3.19, Rosetta Biosoftware; Seattle, WA, USA). Elucidator performed the retention time (RT) alignment, feature identification and extraction for all samples using the Rosetta PeakTeller algorithm. Dynamic background subtraction, smoothing in RT and $\mathrm{m} / \mathrm{z}$ 
dimensions and isotopic regions creation for peak-matching across all runs were calculated using an RT correction of 4 min at the maximum. A single data file was randomly chosen as the master, and all other sample files were aligned to the master in form of a dynamic RT shift. This procedure allowed the improved identification of peptides and proteins in each sample by taking the available data of all samples into account. Features were normalized based on total ion current (TIC). Only features detected in both replicates and in $>80 \%$ of samples were included in further analyses. Protein abundance changes were determined using the MSstats2.15 package ${ }^{35}$ (version 2.3.4) based on linear mixed-effects models under default settings, following $\log _{2}$ transformation and quantile normalization. The model regards features mapped to the same protein as replicate measurements of protein abundance. The model is then used for pairwise comparisons of protein abundances across groups. The tests are performed by deriving model-based estimates for the protein in each group by maximum likelihood. The difference of the estimates is then considered relative to its estimated variation and compared to the student's t-distribution. Proteins with less than 2 peptides (of which at least one had to be unique) were excluded. The $p$-values were adjusted to control for the false discovery rate (FDR) at a cut-off of 0.05 following the Benjamini-Hochberg procedure. $^{28}$

\section{Label-based selected reaction monitoring (SRM) mass spectrometry}

Digested frontal cortex and hippocampus proteomes were analysed using targeted SRM mass spectrometry on a Xevo TQ-S mass spectrometer (Waters Corporation; Milford, CT, USA) coupled to a nanoAcquity UPLC system (Waters Corporation) as described previously. ${ }^{32 b, 36}$ The system was comprised of a C18 trapping column $(180 \mu \mathrm{m} \times 20 \mathrm{~mm}, 5 \mu \mathrm{m}$ particle size $)$ and a C18 BEH nano-column $(75 \mu \mathrm{mx} 200 \mathrm{~mm}, 1.7 \mathrm{~mm}$ particle size). The buffers used for separation were (A) $0.1 \%$ formic acid and (B) $0.1 \%$ formic acid in acetonitrile and the 
following 48 min gradient was applied: $97 / 3 \%$ (A/B) to $60 / 40 \%$ in $30 \mathrm{~min} ; 60 / 40 \%$ to $15 / 85 \%$ in $2 \mathrm{~min} ; 5 \mathrm{~min}$ at $15 / 85 \%$; returning to the initial condition in $1 \mathrm{~min}$. The flow rate was $0.3 \mu \mathrm{L} / \mathrm{min}$ and the column temperature was $35^{\circ} \mathrm{C}$.

Multiplex SRM assays were developed using a high-throughput strategy. ${ }^{37}$ All peptides containing amino acids prone to undergo modifications (e.g., Met, Trp, Asn and Gln), potential ragged ends, or those with lysine/arginine followed by proline or bearing NXT/NXS glycosylation motifs were avoided and only selected when no other options were available. ${ }^{38}$ Criteria for selecting tryptic peptides were based on peptide count, uniqueness and quality of transitions. Transitions were selected based on software internal predictions, discovery proteomics data and spectral data [NIST spectral libraries ${ }^{39}$ ] and calculated using Skyline version 1.2.0.3425. ${ }^{40}$ Quantitative SRM measurements comparing cPCP treated rats and controls were performed in scheduled SRM acquisition mode. Heavy isotope labelled peptide versions (JPT Peptide Technologies GmbH, Berlin, Germany) were spiked in the peptide mixture for accurate quantification and identification. All SRM functions had a $2 \mathrm{~min}$ window of the predicted retention time and scan times were $20 \mathrm{~ms}$. For each peptide, at least three transitions were monitored for the heavy and light versions. The final transitions, collision energies and retention time windows used for each peptide can be found in the supplementary information (Table S1a, Table S1b). Samples were run randomized and blocked $^{41}$ in triplicates, and blanks and quality control peptide injections (yeast alcohol dehydrogenase; Table S1c) were run alternating after each biological replicate. Resulting SRM data were analyzed using Skyline and statistical analysis, testing for differential abundance among cPCP treated rats and control animals, was conducted using MSstats. ${ }^{42}$ Data pre-processing consisted of a $\log _{2}$ transformation to stabilise the variance. Quantile normalization was performed based on reference transitions to equalize the median peak intensities of reference transitions from all proteins across all MS runs and adjust the bias to 
both reference and endogenous signals. Protein level quantification and testing for differential abundance among chronic PCP treated rats and control animals were carried out using the linear mixed-effects model implemented in the R-package MSstats 2.3.4, which employs a "restricted" scope of conclusions (default settings). ${ }^{43}$ In the restricted scope model, the individual samples being modelled are the population of interest. This approach also took into account the measurement error of transitions across runs (technical variation), to enable accurate quantification of protein abundance changes across the samples. Furthermore, the model accounts for the shared run membership of the endogenous and reference transition pairs and normalizes each endogenous transition with respect to its reference. The $p$-values were adjusted to control the false discovery rate at a cut-off of 0.05 according to Benjamini and Hochberg ${ }^{28}$.

\section{Protein set enrichment analysis}

Protein set enrichment analysis was carried out as described previously. ${ }^{44}$ Therefore, significantly changed proteins were partitioned into three bins, according to their ratio: ratio $<1.0$; ratio $>1.0$ and ratio both $>1,<1$. The $\mathrm{R}$ package database org.mouse.eg.db version 2.8.0 was used for gene ontology $(\mathrm{GO})$ term annotation and significant over-representation of an annotated GO term in each bin was determined by the GOstats package (Falcon and Gentleman, 2007). $P$-values for the GO category ${ }^{45}$ "biological pathway" (BP) were calculated by a conditional hypergeometric test, using the entire detected proteome as a background. One-way hierarchical clustering using "Euclidean distance" as distance function and the "Average Linkage Clustering" method available in the Genesis software, ${ }^{46}$ was performed on all significantly enriched GO terms. 


\section{Results \\ Serum Profiling}

We measured serum levels of 89 analytes in rats following cPCP or vehicle treatment using multiplex immunoassays. This was carried out to elucidate how the effects of cPCP treatment are manifested in the peripheral circulation and to identify possible surrogate biomarkers for schizophrenia. In total, 64 analytes were robustly measured with less than $30 \%$ missing values. The list of all measured analytes can be found in Table S2. Following data quality assessment, normalization and scaling, the analysis of the multiplex immunoassays resulted in the identification of five significantly altered analytes in cPCP rat serum $(p<0.05)$ (Table 1). These were predominantly interleukins (IL-5, IL-2, IL-1 $\beta$ ) as well as fibroblast growth factor-2 (FGF-2) and the macrophage inflammatory protein 1a (MIP-1 $\alpha)$.

\section{Label-free $L C-M S^{E}$ proteomic profiling of frontal cortex and hippocampus tissue} Total lysis fractions were prepared from frontal cortex and hippocampus tissue of cPCP and vehicle-treated rats and analysed by label-free LC-MS ${ }^{\mathrm{E}}$. This resulted in identification of 555 proteins in the frontal cortex and 937 proteins in the hippocampus. Of these, 79 proteins $(14 \%)$ were significantly changed due to cPCP treatment in the frontal cortex and 501 proteins (53\%) were altered in the hippocampus (Figure 1, Tables S3a and S3b). We detected protein level alterations of 22 enzymes in the frontal cortex of which 10 (45\%) catalyze a metabolic reaction, and of 139 enzymes in the hippocampus of which 94 (68\%) catalyze a metabolic reaction. The most prominent proteomic alterations $(\mathrm{FC}> \pm 1.2$, $p^{*<0.05)}$ in both regions can be found in Table 2 .

\section{Global metabolic profiling of frontal cortex and hippocampus tissue via UPLC-MS}

We employed UPLC-MS for global metabolic profiling analysis of brain tissue. We identified 1057 metabolite features/peaks after filtering based on relative standard deviation across both models and regions. We were not able to detect any significant changed features 
in the frontal cortex of the cPCP rat model $\left(p^{*}<0.05\right)$ but we found 426 significant changed features $\left(p^{*}<0.05\right)$ in the hippocampus. The metabonomic profiling findings were consistent with the proteomic profiling results, showing a greater effect of PCP in the hippocampus

(Figure 1). For metabolite peak identification, the top 10 significant hits for the brain regions were selected and database identification performed using the HMDB and the Pubchem database (Table S4a and S4b). The identifications are preliminary as databank searches alone don't allow for adequate identification. Tandem MS/MS analysis for metabolite identification were not performed.

\section{Label-free $\mathrm{LC}-\mathrm{MS}{ }^{\mathrm{E}}$ proteomic profiling based pathway analysis}

Pathway analysis was performed using the total of all changed proteins in the frontal cortex and the hippocampus $\left(p^{*}<0.05\right)$ regardless of the magnitude of change. Recent studies have shown that even slight variations in the expression of multiple proteins can result in pathway alterations that might underlie complex disorders. Pathway analysis in combination with quantitative mass spectrometry can help to identify functional links or causality of complex physiological crosstalk in an in-vivo context. The method provides unbiased insights pinpointing pathways underlying physiological changes.

Using Ingenuity Pathway Analysis we identified a decrease in neurodevelopment associated biological functions in the frontal cortex. The hippocampus was associated with a decreased activation of the biological processes "plasticity of synapse", "exocytosis of vesicles", "behaviour" and "spatial memory", and an increased activation of "movement of rodents", "paralysis" and "conditioning" (Figure 3A). This matches the reported behavioural readouts associated with the $\mathrm{CPCP}$ animal model in the literature. ${ }^{47}$

GO-enrichment analysis of the proteomic changes revealed that numerous molecular pathways are affected through the cPCP treatment (Figure 2C), indicating that changes in 
one pathway ultimately lead to changes in the whole system. The most robust enriched biological functions across both brain regions were associated with small GTPases and Rho signalling proteins.

We further investigated which pathways appear to be affected by examining the interactome of the altered proteins. This overcomes the limitations to be restricted to the range of detectable proteins in the QTOF study, where certain protein classes (e.g. low abundant proteins, membrane proteins etc.) are frequently not identified and consequently associated pathways will not appear to be enriched. Therefore, we created cytoscape networks based on significantly changed proteins and their interactors using experimentally defined interaction databases for each comparison. GO-term cluster analysis using the reactome pathway information was performed to derive frontal cortex and hippocampus protein networks and an overlap of significant functions was created to identify the most robust pathway signatures across both regions (Figure 2B). The protein changes appeared to reflect changes in postsynaptic NMDAR activation events, including "Ras activation upon $\mathrm{Ca}^{2+}$-influx through NMDAR" and "CREB phosphorylation through the activation of Ras or CaMKII" as well as two other pathways downstream of the NMDAR. Furthermore the apoptosis-related biological functions of "activation of BAD and BH-3 only proteins" seem to be affected in the frontal cortex. In the case of the hippocampus, a diverse set of other clusters of associated biological functions were found to be enriched in the interactome. This involved AMPA receptor (AMPAR) signalling, kainate receptor signalling, ERK signalling and the TCA cycle.

\section{Selected reaction monitoring validation}

We used selective reaction monitoring assays to validate the findings of the proteomic profiling analysis and in order to follow up implications of the bioinformatic pathway changes. Therefore we included key proteins of glutamatergic signalling and proteins already 
known to be affected by PCP treatment ${ }^{22,24}$ or in schizophrenia. This led to validation of opposite changes in superoxide dismutase and alpha-actinin 1 (ACTN1) in frontal cortex and hippocampus. Furthermore we validated changes in protein DJ1 (PARK7), the astrocytic phosphoprotein 15 (PEA15) and found alterations, although with opposing directional change, in disks large homolog 4 (DLG4), NADH-ubiquinone oxidoreductase $75 \mathrm{kDa}$ subunit (NDUS1) and neurochondrin (NCDN) (Table 3). 


\section{Discussion}

Currently there is only limited understanding of the molecular pathology underlying schizophrenia. The study of animal models used in drug discovery efforts of schizophrenia can help to decipher the molecular neurobiology of this complex disorder and identify novel targets for improved treatment. However, limited progress has been made in developing novel pharmaco-therapies, partly due to the scarcity of well-characterized animal models. In this study, we investigated the molecular changes associated with cPCP treatment in rats using a combination of quantitative Omics-based technologies. This combined approach will help to increase confidence in the validity of the model at the molecular level and thus aid drug discovery studies.

This is the largest study of the PCP rat model carried out to date using a combination of Omics technologies to analyze distinct brain regions which have been implicated in schizophrenia. Alongside, we carried out a molecular profiling of blood serum to increase our understanding of the associated systemic effects as recent studies have shown that noncompetitive NMDAR antagonists modulate immune-regulatory function. ${ }^{48}$ The serum profiling led to identification of changes in fibroblast growth factor-2 (FGF-2) and four cytokines/chemokines (IL-2, IL-5, IL-1 $\beta$, MIP-1 $\alpha$ ). These surrogate markers can be translated to the clinic, where the use of blood serum or plasma can be used for translational studies. After PCP treatment, a general trend towards an anti-inflammatory state was observed with decreased cell-mediated immune responses observed via decreased levels of MIP-1 $\alpha$ [chemoattractant of inflammatory cells], IL-6 [T cell maturation] and IL-5 [immunoglobulin secretion and eosinophil activation]. However, an early immune response was also observed through increased levels of IL-1 $\beta$. When compared to one of our previous studies using the same multiplex immunoassay to investigate serum analyte alterations after acute PCP $(5 \mathrm{mg} / \mathrm{kg})$ treatment $^{22}$, no overlapping alterations in analyte levels were identified. 
In contrast to chronic treatment, acute PCP treatment appears to have a stronger effect on endocrine function, as shown by changes in the levels of several hormones.

Cytokine abnormalities have been frequently associated with schizophrenia ${ }^{49}$ and antipsychotic treatment. ${ }^{50}$ It has been reported that interleukin IL-2 levels can be correlated with the negative symptoms and cognitive performance. ${ }^{51}$ IL- $1 \beta$ has been associated with first episode psychosis, ${ }^{49}$ paranoid schizophrenia ${ }^{52}$ and a meta-analysis of 23 studies, comprising of 762 patients showed that antipsychotic treatment significantly reduced plasma levels of IL-1 $\beta$ in schizophrenia-spectrum disorders. ${ }^{50}$ MIP-1 $\alpha$ has been associated with different psychiatric disorders, implying a general involvement of chemokine systems with psychiatric diseases. ${ }^{53}$ In line with this, elevated levels of serum IL-5 have been associated with an increased likelihood to develop MDD. ${ }^{54}$

This study is the first to describe a robust decrease of FGF-2 in PCP-treated rats. FGF-2 has been implicated in the pathophysiology of schizophrenia and the mechanism of action of antipsychotic treatment response. ${ }^{55}$ Furthermore, it has also been implicated in depression ${ }^{56}$ and as a marker of antidepressant effects. ${ }^{57}$ Based on the psychotomimetic and antidepressant effect of NMDAR-antagonists, especially ketamine, perturbations of FGF-2 regulation might be relevant for both disorders. Future work needs to clarify if these peripheral changes contribute to the specific effect of PCP. With respect to the brain pathology, it is likely that FGF-2 levels in serum resemble levels in the brain since this growth factor can cross the blood-brain barrier. ${ }^{58}$ FGF-2 has been implicated in neurogenesis and gliogenesis during development as well as in adulthood ${ }^{59}$ via its role as a neurotrophic factor. This is consistent with our findings of a strong PCP effect on the hippocampal proteome and metabonome, with respect to the number of molecular changes. A growing number of studies have shown that pre- and postnatal exposure to inflammatory stimuli can modulate the number of proliferating 
and differentiating neural progenitors in the hippocampus and this may have an effect on behaviours relevant to psychiatric disorders. ${ }^{60}$

In general, the brain tissue profiling identified changes in a wide range of proteins induced by cPCP treatment. Individually, protein changes were subtle indicating homeostatic disequilibrium. Therefore we employed several pathway analyses incorporating all changes to reveal which signalling networks and cellular mechanism are dysregulated. In table 2 we also pinpoint proteins with larger fold-changes, which might represent the key drivers for the identified pathway alterations.

Many of these proteins were associated with the post-synaptic density and downstream signal transduction pathways of the NMDAR, the primary target of PCP. Bioinformatic pathway analysis of these proteomic alterations revealed an association with events downstream of NMDA-receptor activation, CREB phosphorylation and $\mathrm{Ca}^{2+}$-influx in both brain regions, which demonstrates the validity of the experimental procedures and provides proof-of-concept of the analytical and bioinformatics approach. To confirm the effects on the postsynaptic density, we validated the alterations in the postsynaptic density protein 95 (DLG4) and actinin 1 (ACTN1) via SRM. ACTN1 interacts with the postsynaptic density network and may play a role in NMDAR and AMPAR localization and modulation of these receptors via effects on $\mathrm{Ca}^{2+}$-flux. ${ }^{61}$

A noteworthy finding of the present study was the greater number of PCP induced proteomic and metabonomic effects in the hippocampus compared to the changes seen in the frontal cortex. This could open up new avenues of research considering that most previous studies on the PCP mechanism of action and schizophrenia pathology have focused on elucidating potential abnormalities in the frontal cortex. ${ }^{62}$ Indeed, hippocampal deficits are an established feature of schizophrenia ${ }^{63}$ as shown by a range of approaches, such as in-vivo (neuropsychology, structural and functional imaging), post-mortem (histology, gene 
expression and neurochemistry) and animal model ${ }^{64}$ studies. Our previous study investigating the effects of acute PCP treatment has indicated that the hippocampus is more affected than the frontal cortex. ${ }^{22}$ Many of the findings of the proteomic shotgun analysis of acute PCP treatment are consistent with findings in this study (Table 3). ${ }^{22}$ Fifteen of the 17 significantly changed proteins in the hippocampus of the acute PCP model overlapped with the findings of this study. The stronger effects induced by chronic treatment might be secondary to neurodegenerative pathologies. Neurodegeneration has been associated with PCP treatment in humans and animal models ${ }^{65}$. Consistent with the proteomic analysis of frontal cortex of a similar cPCP rat model, ${ }^{24}$ we also only detected subtle changes in the frontal cortex. In comparison to this study, we detected overlapping pathways in oxidative stress (DJ-1 and SODC1 proteins) and mitochondrial related proteins (GOT2 and PKLR), and calcium signalling. For instance, neurogranin, one of the strongest alterations which we found in the frontal cortex, regulates calmodulin affinity for $\mathrm{Ca}^{2+}$.

In this investigation, we also identified proteomic correlates for behavioural functions based on hippocampus proteomic abnormalities, such as decreased activation of "behaviour" and "spatial memory" derived from the $\mathrm{cPCP}$-induced hippocampus proteome alterations as well as increased activation of the biological functions "movement", "paralysis" and "conditioning". In the case of the frontal cortex the study was unable to identify any associations of the proteomic alterations with behavioural readouts. The hippocampal alterations were further associated with decreased plasticity of synapse and neurotransmitter release at the proteome level and lipid metabolism at the metabonome level. The hippocampal pathology in schizophrenia appears to be linked with at least some of the cognitive deficits, given the central mnemonic roles of this brain region. ${ }^{66}$ These key changes most likely reflect alterations in the precise organisation and functioning of neural circuits which connect it with other structures, notably the prefrontal cortex. 
Post-mortem studies have provided increasing evidence for glutamatergic neurotransmission abnormalities in schizophrenia. Such studies have found hippocampal changes including reduced expression of one or more subunits for all three ionotropic glutamate receptors (NMDAR, AMPAR, and kainite receptor). In addition, recently described susceptibility genes for schizophrenia all act upon glutamatergic synaptic transmission, which may be part of the core pathophysiology. ${ }^{67}$ We identified PCP-induced alterations in proteins involved in AMPAR trafficking in the hippocampus, which is one of the key mechanisms of synaptic plasticity. Studies have shown that NMDAR channel opening and the subsequent rise in postsynaptic calcium concentrations during repetitive synaptic activity, leads to regulated trafficking of postsynaptic AMPARs into and out of excitatory synapses. Targeting AMPAR signalling might therefore, represent a novel target in schizophrenia research.

This study also detected changes in $\mathrm{Ca}^{2+}$, opioid, kainate and ERK signalling, which have previously been associated with NMDAR hypofunction. ${ }^{32 b, 68}$ For instance, repeated administration of PCP reduces sigma-1 receptors in the hippocampus. ${ }^{13}$ Interestingly, effects on neurotransmitter metabolism were identified in the hippocampus, as shown by IPA and cytoscape pathway analysis. The most robust protein findings were associated with GABAreceptor pathways. A compromised GABAergic system has been hypothesized to be involved in schizophrenia. Notably, NMDAR hypofunction has been proposed to promote deficits in GABAergic signalling ${ }^{69}$ and PCP administration during neurodevelopment affects the functionality of GABA interneurons in later life. ${ }^{70}$ One action of NMDA antagonists is to reduce the excitation of fast-spiking GABA interneurons, resulting in disinhibition of pyramidal cells. Overactive pyramidal cells, notably those in the hippocampus, can induce a hyperdopaminergic state that produces psychosis. ${ }^{69}$ 
Finally, we identified alterations in the protein level of the superoxide dismutase enzyme (SODC) in both the frontal cortex and hippocampus, which is part of the reactive oxygen species (ROS) defence system. Oxidative stress damages many cell structures such as protein, lipids and $\mathrm{DNA}^{71}$. Impairments in energy metabolism are common traits of psychiatric disorders and were previously identified by functional assays, gene and protein expression studies as well as linkage analysis in schizophrenia patients. ${ }^{72} \mathrm{PCP}$ administration to rats results in reduced rates of oxygen uptake into mitochondria isolated from brain tissue ${ }^{73}$ and a meta-analysis of 44 studies identified a total antioxidant status in serum and plasma as a state marker for first-episode psychosis. ${ }^{74}$ For these reasons, molecules that possess antioxidant and anti-inflammatory properties may be useful as potential novel treatments in the first stages of schizophrenia. ${ }^{75}$

This comprehensive proteomic and metabonomic study of the cPCP rat model provides novel molecular evidence showing that different neurotransmitter systems are affected through PCP treatment and that these effects occur primarily in the hippocampus. Importantly we were able to find potential molecular correlates which may be linked to the behavioural readouts in this model. Further studies are warranted to investigate this possibility as this could lead to identification of novel therapeutic targets involved in regulation of psychiatric symptoms. Furthermore, understanding the changes in glutamate neurotransmission in schizophrenia may facilitate the discovery of novel targets for pharmacological interventions, which are especially needed for the cognitive and negative symptoms in schizophrenia. 


\section{ASSOCIATED CONTENT}

\section{Supporting Information.}

Supplementary Tables S1a-c, 2, 3a,b and 4a,b. This material is available free of charge via the Internet at http://pubs.acs.org."

\section{AUTHOR INFORMATION}

\section{Corresponding Author}

*corresponding author: Professor Sabine Bahn, *Department of Chemical Engineering and Biotechnology, University of Cambridge, Cambridge, Tennis Court Road, CB2 1QT, UK Tel: +44 (0) 1223334151, e-mail: sb209@cam.ac.uk (e-mail: sb209@cam.ac.uk)

\section{Author Contributions}

The manuscript was written through contributions of all authors. All authors have given approval to the final version of the manuscript.

\section{ACKNOWLEDGMENTS}

This research was kindly supported by the Stanley Medical Research Institute (SMRI), the Innovative Medicines Initiative for Novel Methods leading to New Medications in Depression and Schizophrenia (IMI NEWMEDS), the Dutch Fund for Economic Structure Reinforcement ((\#0908) the NeuroBasic PharmaPhenomics project. EJW acknowledges Waters Corporation for funding.

\section{CONFLICT OF INTEREST}

S.B. is a director of Psynova Neurotech Ltd. The other authors declare no conflict of interest. 


\section{TABLES.}

Table 1: Analysis of protein levels in serum of PCP-treated $(n=8)$ and saline-treated rats (n=8) using multiplexed immunoassays. $P$-Values were determined using SAM ${ }^{27} \mathrm{FC}=$ Fold change. $\mathrm{CT}=$ vehicle-treated rats

Table 2: Most robust differentially expressed proteins identified in the frontal cortex and hippocampus of chronic PCP-treated rats compared to vehicle-treated rats using label-free $\mathrm{LC}_{-\mathrm{MS}}{ }^{\mathrm{E}}$ (ratio of $<0.80$ or $>1.20, \mathrm{p}^{*}<0.05$ ). PC $=$ peptide count

Table 3: Significantly changed proteins identified via label-based LC-SRM in the frontal cortex and hippocampus of cPCP-treated rats compared to vehicle-treated rats. Grey bars show consistency between SRM and LC-MS ${ }^{\mathrm{E}}$ analysis. 
TABLE 1

\begin{tabular}{|c|c|c|c|c|c|}
\hline Analyte name & $\begin{array}{l}\text { UniProt } \\
\text { ID }\end{array}$ & $\begin{array}{l}\text { Gene } \\
\text { name }\end{array}$ & $\begin{array}{c}\text { Ratio } \\
\text { CPCP/CT }\end{array}$ & $p$ & $p^{*}$ \\
\hline Interleukin-5 (IL-5) & Q08125 & 115 & -1.73 & $<0.001$ & $<0.001$ \\
\hline Fibroblast Growth Factor-basic (FGF-2) & P13109 & Fgf-2 & -1.35 & $<0.001$ & $<0.001$ \\
\hline Interleukin-2 (IL-2) & P17108 & $\| 2$ & -1.60 & 0.0018 & 0.0397 \\
\hline Macrophage Inflammatory Protein- $1 \alpha$ (MIP-1alpha) & P50229 & $\mathrm{Ccl} 3$ & -1.35 & 0.0029 & 0.0472 \\
\hline Interleukin-1beta (IL-1beta) & Q63264 & $\| 1 b$ & 1.10 & 0.0104 & 0.1332 \\
\hline
\end{tabular}




\section{TABLE 2:}

\begin{tabular}{|c|c|c|c|c|c|c|c|}
\hline Uniprot & Entry & Gene name & Protein names & PC & Ratio & $p^{*}$ & Biological functions \\
\hline \multicolumn{8}{|c|}{ Frontal Cortex } \\
\hline NEUG & Q04940 & Nrgn & Neurogranin (Ng) & 5 & 0.80 & $2.9 \mathrm{E}-06$ & Regulates calmodulin affinity for $\mathrm{Ca}^{2+}$. Involved in synaptic plasticity and spatial learning \\
\hline KIF15 & Q7TSP2 & Kif15 & Kinesin-like protein KIF15 & 2 & 0.82 & $1.3 \mathrm{E}-05$ & Plus-end directed kinesin-like motor enzyme involved in mitotic spindle assembly \\
\hline SNAB & P85969 & $\mathrm{Napb}$ & Beta-soluble NSF attachment protein & 2 & 0.83 & $2.2 \mathrm{E}-03$ & Required for vesicular transport between endoplasmic reticulum and Golgi apparatus \\
\hline PGCB & P55068 & Bcan & Brevican core protein & 2 & 1.28 & $2.6 \mathrm{E}-03$ & May play a role in the adult nervous system during postnatal development \\
\hline CLC11 & 088200 & Clec11a & C-type lectin domain family 11 member $\mathrm{A}$ & 2 & 1.31 & $2.0 \mathrm{E}-06$ & Acts synergistically with other cytokines, including IL-3, GCSF, GMCSF and FLT3 ligand. \\
\hline М3К9 & Q3U1V8 & Map3k9 & Mitogen-activated protein kinase kinase kinase 9 & 2 & 1.20 & 3.4E-02 & Serine/threonine kinase in MAP kinase signal transduction pathway \\
\hline \multicolumn{8}{|c|}{ Hippocampus } \\
\hline AP2M1 & P84092 & Ap2m1 & AP- 2 complex subunit mu & 9 & 1.18 & $<\mathrm{E}-16$ & Functions in protein transport via transport vesicles in different membrane traffic pathways \\
\hline BIEA & P46844 & Blvra & Biliverdin reductase $\mathrm{A}$ (EC 1.3.1.24) & 2 & 1.58 & $<\mathrm{E}-16$ & Reduces biliverdin IX alpha to bilirubin \\
\hline CP239 & P56656 & Сур2с39 & Cytochrome P450 2C39 (EC 1.14.14.1) & 3 & 0.75 & $<\mathrm{E}-16$ & Cytochrome P450 2C39 \\
\hline GP128 & Q8BM96 & Gpr128 & Probable G-protein coupled receptor 128 & 2 & 0.77 & $<\mathrm{E}-16$ & Orphan receptor \\
\hline $\mathrm{H} 2 \mathrm{~A} 2 \mathrm{~A}$ & Q6GSS7 & Hist2h2aa1 & Histone $\mathrm{H} 2 \mathrm{~A}$ type $2-\mathrm{A}$ & 3 & 1.52 & $<\mathrm{E}-16$ & DNA packaging \\
\hline $\mathrm{H} 2 \mathrm{AX}$ & P27661 & H2afx & Histone $\mathrm{H} 2 \mathrm{AX}$ & 4 & 1.37 & $<\mathrm{E}-16$ & DNA packaging \\
\hline IDUA & P48441 & Idua & Alpha-L-iduronidase (EC 3.2.1.76) & 3 & 1.31 & $<\mathrm{E}-16$ & Hydrolysis of unsulfated alpha-L-iduronosidic linkages in dermatan 27 ulphate. \\
\hline PLIN3 & Q9DBG5 & Plin3 & Perilipin-3 & 2 & 1.38 & $<\mathrm{E}-16$ & Required transport of mannose 6-phosphate receptors from endosomes to trans-Golgi network \\
\hline SLX4I & Q9D7Y9 & Slx4ip & Protein SLX4IP & 2 & 0.40 & $<\mathrm{E}-16$ & Subunit of different structure-specific endonucleases \\
\hline PGTA & Q08602 & Rabggta & Geranylgeranyl transferase type- 2 subunit alpha & 2 & 1.26 & $1.0 \mathrm{E}-14$ & Catalyzes the transfer of geranylgeranyl moiety to Rab proteins. \\
\hline ANR26 & Q811D2 & Ankrd26 & Ankyrin repeat domain-containing protein 26 & 2 & 0.71 & $3.9 \mathrm{E}-14$ & Unknown biological function \\
\hline STAG2 & 035638 & Stag2 & Cohesin subunit SA-2 & 3 & 1.38 & $1.2 \mathrm{E}-13$ & Component of cohesin complex (DNA replication) \\
\hline MEP1A & P28825 & Mep1a & Meprin A subunit alpha (EC 3.4.24.18) & 3 & 1.29 & $2.9 \mathrm{E}-13$ & Hydrolysis of protein/peptide substrates preferentially on carboxyl side of hydrophobic residues \\
\hline H2A1F & Q64598 & Hist1h2af & Histone $\mathrm{H} 2 \mathrm{~A}$ type $1-\mathrm{F}$ & 3 & 1.32 & $1.8 \mathrm{E}-12$ & Core component of nucleosome. Nucleosomes wrap and compact DNA into chromatin \\
\hline TRAF5 & P70191 & Traf5 & TNF receptor-associated factor 5 & 2 & 1.24 & $1.6 \mathrm{E}-10$ & Links members of the tumor necrosis factor receptor family to different signaling pathways \\
\hline CC183 & A2AJB1 & Ccdc183 & Coiled-coil domain-containing protein 183 & 2 & 0.79 & $8.4 \mathrm{E}-10$ & Unknown biological function \\
\hline PCLI1 & Q3UBG2 & Pid1 & PTB-containing, cubilin and LRP1-interacting protein & 2 & 0.78 & $8.9 \mathrm{E}-10$ & Increases proliferation of preadipocytes without affecting adipocytic differentiation \\
\hline FMN1 & Q05860 & Fmn1 & Formin-1 & 2 & 0.8 & $1.1 \mathrm{E}-09$ & Plays a role in the formation of adherens junction and the polymerization of linear actin cables \\
\hline VGLU1 & Q62634 & Slc17a7 & Vesicular glutamate transporter 1 & 4 & 1.21 & $1.4 \mathrm{E}-09$ & Mediates glutamate uptake into synaptic vesicles in excitatory neural cells. \\
\hline CCD67 & Q7M6Y5 & Ccdc67 & Deuterosome protein 1 & 2 & 0.79 & $2.0 \mathrm{E}-08$ & Key structural component of the deuterosome (de novo centriole amplification) \\
\hline FOXK1 & P42128 & Foxk1 & Forkhead box protein K1 & 2 & 0.65 & $6.1 \mathrm{E}-08$ & Transcriptional regulator that binds to the upstream enhancer region \\
\hline PA1B2 & 035264 & Pafah1b2 & PAF-AH subunit beta & 3 & 0.80 & $8.9 \mathrm{E}-08$ & Inactivates the platelet-activating factor \\
\hline RENI2 & P00796 & Ren2 & Renin-2 & 2 & 1.32 & $8.9 \mathrm{E}-08$ & Endopeptidase, generates angiotensin I from angiotensinogen in the plasma \\
\hline ACBP & P11030 & Dbi & Acyl-CoA-binding protein & 3 & 1.21 & $9.0 \mathrm{E}-08$ & Acts as a neuropeptide to modulate the action of the GABA receptor \\
\hline UGPA & Q91ZJ5 & Ugp2 & UTP--glucose-1-phosphate uridylyltransferase & 3 & 1.51 & $1.4 \mathrm{E}-07$ & Central role as a glucosyl donor in cellular metabolic pathways \\
\hline DDX28 & Q9CWT6 & Ddx28 & Probable ATP-dependent RNA helicase DDX28 & 2 & 1.23 & $7.2 \mathrm{E}-06$ & Involved in RNA processing or transport \\
\hline TRM11 & Q9CWH5 & Trmt11 & tRNA (guanine(10)-N2)-methyltransferase homolog & 2 & 1.23 & 3.5E-05 & Mediates guanosine nucleotide methylation at position 10 \\
\hline GBRG2 & P18508 & Gabrg2 & Gamma-aminobutyric acid receptor subunit gamma-2 & 2 & 1.22 & $6.5 \mathrm{E}-05$ & GABA receptor, mediates neuronal inhibition \\
\hline TPM4 & P09495 & Tpm4 & Tropomyosin alpha-4 chain & 2 & 1.64 & $1.1 \mathrm{E}-04$ & Implicated in stabilizing cytoskeleton actin filaments, binds calcium \\
\hline TMOD2 & P70566 & Tmod2 & Tropomodulin-2 & 2 & 1.24 & $7.0 \mathrm{E}-03$ & Blocks the elongation and depolymerization of the actin filaments at the pointed end \\
\hline CBX8 & Q9QXV1 & $\mathrm{Cbx} 8$ & Chromobox protein homolog 8 & 2 & 0.77 & $1.1 \mathrm{E}-02$ & In complex that maintains transcriptionally repressive state of many genes \\
\hline
\end{tabular}




\section{TABLE 3}

\begin{tabular}{|c|c|c|c|c|c|c|c|c|c|c|c|c|c|c|c|c|c|}
\hline \multirow[b]{2}{*}{ Biological Pathway/Function } & \multirow[b]{2}{*}{ SZ } & \multirow[b]{2}{*}{$\begin{array}{l}\text { CPCP } \\
\text { FC }\end{array}$} & \multirow[b]{2}{*}{$\begin{array}{c}\text { aPCP } \\
\text { HC }\end{array}$} & \multirow[b]{2}{*}{ Uniprot-ID } & \multirow[b]{2}{*}{$\begin{array}{c}\text { Gene } \\
\text { name }\end{array}$} & \multicolumn{6}{|c|}{$\begin{array}{l}\text { Frontal Cortex } \\
10 \text { cPCP vs } 7 \mathrm{CT} \\
\end{array}$} & \multicolumn{6}{|c|}{$\begin{array}{l}\text { Hippocampus } \\
9 \text { cPCP vs } 7 \text { CT }\end{array}$} \\
\hline & & & & & & \multirow{2}{*}{$\begin{array}{l}\text { TPP } \\
4 \mid 4\end{array}$} & \multicolumn{2}{|c|}{$\begin{array}{c}\text { Ratio } \\
\text { PCP/Ctrl }\end{array}$} & \multirow{2}{*}{$\frac{p}{3.51 \mathrm{E}-06}$} & \multirow{2}{*}{$\frac{p^{*}}{2.63 \mathrm{E}-05}$} & \multirow{2}{*}{$\frac{\text { LC-MS }^{\mathrm{E}}}{\left({ }^{*}\right) \nabla}$} & \multirow{2}{*}{$\begin{array}{l}\text { TPP } \\
2 \mid 4\end{array}$} & \multicolumn{2}{|c|}{$\begin{array}{c}\text { Ratio } \\
\text { PCP/Ctrl }\end{array}$} & \multirow{2}{*}{$\begin{array}{c}\boldsymbol{p} \\
3.87 \mathrm{E}-03\end{array}$} & \multirow{2}{*}{$\begin{array}{c}\boldsymbol{p}^{*} \\
1.45 \mathrm{E}-02\end{array}$} & \multirow{2}{*}{$\frac{\text { LC-MS }}{{ }^{*} \boldsymbol{\Lambda}}$} \\
\hline Alpha-actinin-1 & & & & Q971P2 & Actn1 & & 0.59 & $\boldsymbol{\nabla}$ & & & & & 1.48 & $\boldsymbol{\Delta}$ & & & \\
\hline Aspartate aminotransferase, mito (EC 2.6.1.1) & $\mathrm{x}$ & $\mathrm{x}$ & & P00507 & Got2 & $6 \mid 7$ & 1.24 & $\Delta$ & $2.15 \mathrm{E}-10$ & 3.23E-09 & n.s. & $5 \mid 7$ & 1.01 & & 7.01E-01 & 7.87E-01 & n.s. \\
\hline Astrocytic phosphoprotein PEA-15 & & & & Q5U318 & Pea15 & 8 & 0.61 & $\boldsymbol{\nabla}$ & 3.05E-04 & $1.20 \mathrm{E}-03$ & n.d. & 8 & 1.18 & $\Delta$ & 3.59E-04 & $1.79 \mathrm{E}-03$ & ${ }^{*} \boldsymbol{\Delta}$ \\
\hline Catechol O-methyltransferase (EC 2.1.1.6) & $\mathbf{x}$ & & & P22734 & Comt & 4 & 0.71 & $\boldsymbol{\nabla}$ & $1.01 \mathrm{E}-02$ & $2.53 \mathrm{E}-02$ & n.d. & 3 & 0.58 & $\boldsymbol{\nabla}$ & $1.14 \mathrm{E}-05$ & $9.25 \mathrm{E}-05$ & n.d. \\
\hline Cofilin-1 & & $\mathbf{x}$ & & P45592 & $\mathrm{Cfl} 1$ & $7 \mid 6$ & 0.85 & $\boldsymbol{\nabla}$ & $1.51 \mathrm{E}-05$ & 9.07E-05 & n.s. & $5 \mid 3$ & 1.05 & & $1.02 \mathrm{E}-01$ & $1.91 \mathrm{E}-01$ & $(*) \nabla$ \\
\hline Coronin-1A & & & & Q91ZN1 & Corola & $5 \mid 4$ & 1.51 & $\boldsymbol{\Delta}$ & $1.61 \mathrm{E}-11$ & 4.82E-10 & n.d. & $5 \mid 2$ & 1.03 & & $6.88 \mathrm{E}-01$ & 7.87E-01 & n.s \\
\hline Disks large homolog 4 & $\mathbf{x}$ & & & P31016 & Dlg4 & $4 \mid 3$ & 0.94 & & 2.92E-01 & 4.87E-01 & n.d. & $3 \mid 3$ & 0.71 & $\boldsymbol{\nabla}$ & $1.18 \mathrm{E}-09$ & $3.55 \mathrm{E}-08$ & ${ }^{* * *} \boldsymbol{\Lambda}$ \\
\hline Hypoxanthine-guanine phosphoribosyltransferase & & & & P27605 & Hprt1 & $4 \mid 5$ & 0.95 & & 3.74E-01 & 5.49E-01 & n.d. & $6 \mid 4$ & 1.02 & & $6.00 \mathrm{E}-01$ & $7.51 \mathrm{E}-01$ & n.d. \\
\hline NADH-ubiquinone oxidoreductase $75 \mathrm{kDa}$ subunit, mito. & & $\mathbf{x}$ & & Q66HF1 & Ndufs1 & $6 \mid 3$ & 0.59 & $\boldsymbol{\nabla}$ & $2.53 \mathrm{E}-06$ & 2.53E-05 & n.s. & $4 \mid 5$ & 1.15 & $\Delta$ & 1.03E-02 & 2.83E-02 & $* * * \boldsymbol{\nabla}$ \\
\hline Neurochondrin & $\mathbf{x}$ & & $\mathrm{x}$ & 035095 & Ncdn & $3 \mid 3$ & 1.09 & & 3.93E-01 & 5.49E-01 & n.d. & $4 \mid 4$ & 0.94 & $\boldsymbol{\nabla}$ & $1.04 \mathrm{E}-02$ & $2.83 \mathrm{E}-02$ & ${ }^{* *} \boldsymbol{\Lambda}$ \\
\hline Profilin-1 & & & & P62963 & Pfn1 & $5 \mid 4$ & 0.98 & & $6.62 \mathrm{E}-01$ & $8.28 \mathrm{E}-01$ & n.s. & $4 \mid 4$ & 0.99 & & $6.00 \mathrm{E}-01$ & $7.51 \mathrm{E}-01$ & n.d. \\
\hline Prohibitin & & $\mathrm{x}$ & & P67779 & $\mathrm{Phb}$ & $4|6| 5$ & 1.00 & & $9.70 \mathrm{E}-01$ & $9.73 \mathrm{E}-01$ & n.s. & $4|5| 5$ & 0.99 & & $7.35 \mathrm{E}-01$ & 7.87E-01 & n.d. \\
\hline Protein DJ-1 (EC 3.4.-.-) & & $\mathrm{x}$ & $\mathrm{x}$ & 088767 & Park7 & 3 & 0.47 & $\boldsymbol{\nabla}$ & $1.82 \mathrm{E}-04$ & $9.12 \mathrm{E}-04$ & $* \boldsymbol{\nabla}$ & 4 & 1.04 & & 5.49E-02 & $1.18 \mathrm{E}-01$ & n.d. \\
\hline Protein Slc25a12 & & & & F1LX07 & Slc25a12 & $3 \mid 4$ & 1.00 & & $9.73 \mathrm{E}-01$ & $9.73 \mathrm{E}-01$ & n.s. & $3 \mid 3$ & 1.09 & & $3.81 \mathrm{E}-01$ & $5.72 \mathrm{E}-01$ & n.d. \\
\hline Ras-related protein Rab-35 & & & & Q5U316 & Rab35 & $4 \mid 5$ & 0.81 & $\boldsymbol{\nabla}$ & $3.21 \mathrm{E}-04$ & $1.20 \mathrm{E}-03$ & n.s. & $3 \mid 4$ & 1.12 & & $1.54 \mathrm{E}-01$ & $2.71 \mathrm{E}-01$ & n.d. \\
\hline Septin-5 & $\mathbf{x}$ & & & Q9IJM9 & Sept5 & $5 \mid 8$ & 0.80 & $\boldsymbol{\nabla}$ & 7.54E-03 & $2.06 \mathrm{E}-02$ & n.s. & $4 \mid 10$ & 1.46 & $\boldsymbol{\Delta}$ & $2.12 \mathrm{E}-07$ & $3.18 \mathrm{E}-06$ & ${ }^{*} \boldsymbol{\Lambda}$ \\
\hline Superoxide dismutase [Cu-Zn] (EC 1.15.1.1) & & $\mathbf{x}$ & & P07632 & Sod1 & 815 & 0.86 & $\boldsymbol{\nabla}$ & $1.28 \mathrm{E}-03$ & 3.83E-03 & ${ }^{* * *} \boldsymbol{\nabla}$ & $4 \mid 5$ & 1.10 & $\Delta$ & $1.23 \mathrm{E}-05$ & $9.25 \mathrm{E}-05$ & ${ }^{*} \boldsymbol{\Delta}$ \\
\hline Vesicular glutamate transporter 1 (VGluT1) & $\mathbf{x}$ & $\mathbf{x}$ & & Q62634 & Slc17a7 & 8 & 1.01 & & 8.01E-01 & $9.00 \mathrm{E}-01$ & n.d. & 6 & 0.96 & & $8.49 \mathrm{E}-02$ & $1.70 \mathrm{E}-01$ & ${ }^{* * *} \boldsymbol{\Lambda}$ \\
\hline
\end{tabular}

Abbreviations: UP-ID $=$ Uniprot-ID, FC $=$ frontal cortex, LC-MS $=$ QTOF profiling, $S Z=$ significantly changed in human post-mortem brain ${ }^{36}, \mathrm{CPCP} F \mathrm{FC}=$ significantly changed in frontal cortex tissue $\mathrm{CPCP}$-treated rats ${ }^{24}$, aPCP = significantly changed in hippocampus tissue aPCP-treated rats ${ }^{22}, \mathrm{TPP}=$ transitions per proteotypic peptide, $\mathbf{\Delta}$, upregulated, $\mathbf{\nabla}$, downregulated. ${ }^{*}, * *$, and ${ }^{* * *} p^{*} \leq 0.05,0.01$, and 0.001, respectively. n.s. $=$ not significant, n.d. = not detected 


\section{FIGURES}

Figure 1: Overview of the proteomic and metabonomic profiling results. Volcano plots of group comparisons showing the adjusted significance values versus fold change distributions. Horizontal grey lines indicate the adjusted $p$ value threshold of 0.05 , vertical grey dotted lines indicate a fold-change threshold of $10 \%$ (proteomics) and 50\% (metabonomics, shown for positive ion mode). Green dots represent down regulated proteins/metabolites, red dots represent up regulated proteins/metabolites. Grey/black dots represent proteins/metabolites not meeting the threshold. $($ Neg. $)=$ negative ion mode. $($ Pos. $)=$ positive ion mode. Full information can be found in the supplementary information.

Figure 2: Computational Pathway analysis of the cPCP-induced proteomic alterations in frontal cortex and hippocampus brain tissue. A) Ingenuity Pathway Analysis (IPA) showing significantly decreased and increased biological functions in $\mathrm{CPCP}$ rat brain regions. Functions $(p<0.05)$ are shown with an activation score (z-score) $>1$ (increased activation) or $<-1$ (decreased activation). B) Functional enrichment analysis of significantly changed proteins in frontal cortex and hippocampus of the cPCP rat. Proteins were split into foldchange bins for separate analyses. Colour coded z-score transformed $p$-values indicate the significance of the enrichment for each bin as indicated. C) Cytoscape generated interaction clusters based on the altered proteins $(p<0.05)$ in the frontal cortex and hippocampus. Protein interaction networks were created using the IMEx databases and ClueGO was applied to identify clusters within. Overlapping GO-terms amongst the clusters are indicated by grey shading. Circles represent different GO-terms within the cluster. 


\section{REFERENCES}

1. (a) Javitt, D. C.; Zukin, S. R., Recent advances in the phencyclidine model of schizophrenia. Am J Psychiatry 1991, 148 (10), 1301-8; (b) Ellison, G., The N-Methyl-D-Aspartate Antagonists Phencyclidine, Ketamine and Dizocilpine as Both Behavioral and Anatomical Models of the Dementias. Brain Research Reviews 1995, 20 (2), 250-267.

2. Neill, J. C.; Harte, M. K.; Haddad, P. M.; Lydall, E. S.; Dwyer, D. M., Acute and chronic effects of NMDA receptor antagonists in rodents, relevance to negative symptoms of schizophrenia: $A$ translational link to humans. European Neuropsychopharmacology 2014, 24 (5), 822-835.

3. (a) Bakker, C. B.; Amini, F. B., Observations on the psychotomimetic effects of Sernyl. Compr Psychiatry 1961, 2, 269-80; (b) Grayson, B.; Adamson, L.; Harte, M.; Leger, M.; Marsh, S.; Piercy, C.; Neill, J. C., The involvement of distraction in memory deficits induced by NMDAR antagonism: Relevance to cognitive deficits in schizophrenia. Behavioural Brain Research 2014, 266, 188-192; (c) Nabeshima, T.; Mouri, A.; Murai, R.; Noda, Y., Animal model of schizophrenia: dysfunction of NMDA receptor-signaling in mice following withdrawal from repeated administration of phencyclidine. Ann N Y Acad Sci 2006, 1086, 160-8; (d) Snyder, S. H., Phencyclidine. Nature 1980, 285 (5764), 355-6; (e) Gastambide, F.; Mitchell, S. N.; Robbins, T. W.; Tricklebank, M. D.; Gilmour, G., Temporally distinct cognitive effects following acute administration of ketamine and phencyclidine in the rat. European Neuropsychopharmacology 2013, 23 (11), 1414-1422.

4. (a) Snyder, S. H., Psychotogenic drugs as models for schizophrenia. Neuropsychopharmacology 1988, 1 (3), 197-9; (b) Jones, C. A.; Watson, D. J. G.; Fone, K. C. F., Animal models of schizophrenia. British Journal of Pharmacology 2011, 164 (4), 1162-1194.

5. Itil, T.; Keskiner, A.; Kiremitci, N.; Holden, J. M., Effect of phencyclidine in chronic schizophrenics. Can Psychiatr Assoc J 1967, 12 (2), 209-12.

6. (a) Kapur, S.; Seeman, P., NMDA receptor antagonists ketamine and PCP have direct effects on the dopamine $\mathrm{D}(2)$ and serotonin 5-HT(2)receptors-implications for models of schizophrenia. Mol Psychiatry 2002, 7 (8), 837-44; (b) Choi, Y. K.; Snigdha, S.; Shahid, M.; Neill, J. C.; Tarazi, F. I., Subchronic effects of phencyclidine on dopamine and serotonin receptors: implications for schizophrenia. J Mol Neurosci 2009, 38 (3), 227-35.

7. (a) Jentsch, J. D.; Elsworth, J. D.; Redmond, D. E., Jr.; Roth, R. H., Phencyclidine increases forebrain monoamine metabolism in rats and monkeys: modulation by the isomers of HA966. $J$ Neurosci 1997, 17 (5), 1769-75; (b) Jentsch, J. D.; Redmond, D. E., Jr.; Elsworth, J. D.; Taylor, J. R.; Youngren, K. D.; Roth, R. H., Enduring cognitive deficits and cortical dopamine dysfunction in monkeys after long-term administration of phencyclidine. Science 1997, 277 (5328), 953-5.

8. (a) Jentsch, J. D.; Tran, A.; Le, D.; Youngren, K. D.; Roth, R. H., Subchronic phencyclidine administration reduces mesoprefrontal dopamine utilization and impairs prefrontal corticaldependent cognition in the rat. Neuropsychopharmacology 1997, 17 (2), 92-9; (b) Jentsch, J. D.; Taylor, J. R.; Roth, R. H., Subchronic phencyclidine administration increases mesolimbic dopaminergic system responsivity and augments stress- and psychostimulant-induced hyperlocomotion. Neuropsychopharmacology 1998, 19 (2), 105-13; (c) Deutch, A. Y.; Tam, S. Y.; Freeman, A. S.; Bowers, M. B.; Roth, R. H., Mesolimbic and Mesocortical Dopamine Activation Induced by Phencyclidine - Contrasting Pattern to Striatal Response. European Journal of Pharmacology 1987, 134 (3), 257-264.

9. Jentsch, J. D.; Roth, R. H., The neuropsychopharmacology of phencyclidine: from NMDA receptor hypofunction to the dopamine hypothesis of schizophrenia. Neuropsychopharmacology 1999, 20 (3), 201-25.

10. (a) Li, Z. M.; Boules, M.; Williams, K.; Peris, J.; Richelson, E., The novel neurotensin analog NT69L blocks phencyclidine (PCP)-induced increases in locomotor activity and PCP-induced increases in monoamine and amino acids levels in the medial prefrontal cortex. Brain Research 2010, 1311, 2836; (b) Snell, L. D.; Yi, S. J.; Johnson, K. M., Comparison of the effects of MK-801 and phencyclidine on catecholamine uptake and NMDA-induced norepinephrine release. Eur J Pharmacol 1988, 145 (2), 
223-6; (c) Millan, M. J.; Brocco, M.; Gobert, A.; Joly, F.; Bervoets, K.; Rivet, J.; Newman-Tancredi, A.; Audinot, V.; Maurel, S., Contrasting mechanisms of action and sensitivity to antipsychotics of phencyclidine versus amphetamine: importance of nucleus accumbens 5-HT2A sites for PCP-induced locomotion in the rat. Eur J Neurosci 1999, 11 (12), 4419-32.

11. Yonezawa, Y.; Kuroki, T.; Kawahara, T.; Tashiro, N.; Uchimura, H., Involvement of gammaaminobutyric acid neurotransmission in phencyclidine-induced dopamine release in the medial prefrontal cortex. Eur J Pharmacol 1998, 341 (1), 45-56.

12. Murray, T. F.; Cheney, D. L., The effect of phencyclidine on the turnover rate of acetylcholine in various regions of rat brain. J Pharmacol Exp Ther 1981, 217 (3), 733-7.

13. Kunitachi, S.; Fujita, Y.; Ishima, T.; Kohno, M.; Horio, M.; Tanibuchi, Y.; Shirayama, Y.; Iyo, M.; Hashimoto, K., Phencyclidine-induced cognitive deficits in mice are ameliorated by subsequent subchronic administration of donepezil: Role of sigma-1 receptors. Brain Research 2009, 1279, 189196.

14. Sams-Dodd, F., Phencyclidine-induced stereotyped behaviour and social isolation in rats: a possible animal model of schizophrenia. Behav Pharmacol 1996, 7 (1), 3-23.

15. Turgeon, S. M.; Hoge, S. G., Prior exposure to phencyclidine decreases voluntary sucrose consumption and operant performance for food reward. Pharmacol Biochem Behav 2003, 76 (3-4), 393-400.

16. Adams, B.; Moghaddam, B., Corticolimbic dopamine neurotransmission is temporally dissociated from the cognitive and locomotor effects of phencyclidine. J Neurosci 1998, 18 (14), 5545-54.

17. (a) Bubenikova-Valesova, V.; Horacek, J.; Vrajova, M.; Hoschl, C., Models of schizophrenia in humans and animals based on inhibition of NMDA receptors. Neurosci Biobehav Rev 2008, 32 (5), 1014-23; (b) Lee, P. R.; Brady, D. L.; Shapiro, R. A.; Dorsa, D. M.; Koenig, J. I., Social interaction deficits caused by chronic phencyclidine administration are reversed by oxytocin. Neuropsychopharmacology 2005, 30 (10), 1883-94; (c) Lipska, B. K.; Weinberger, D. R., To model a psychiatric disorder in animals: schizophrenia as a reality test. Neuropsychopharmacology 2000, 23 (3), 223-39.

18. (a) Iltis, I.; Koski, D. M.; Eberly, L. E.; Nelson, C. D.; Deelchand, D. K.; Valette, J.; Ugurbil, K.; Lim, K. O.; Henry, P. G., Neurochemical changes in the rat prefrontal cortex following acute phencyclidine treatment: an in vivo localized (1)H MRS study. NMR Biomed 2009, 22 (7), 737-44; (b) Jentsch, J. D.; Sanchez, D.; Elsworth, J. D.; Roth, R. H., Clonidine and guanfacine attenuate phencyclidine-induced dopamine overflow in rat prefrontal cortex: mediating influence of the alpha2A adrenoceptor subtype. Brain Res 2008, 1246, 41-6; (c) Zuo, D. Y.; Bzdega, T.; Olszewski, R. T.; Moffett, J. R.; Neale, J. H., Effects of N-Acetylaspartylglutamate (NAAG) Peptidase Inhibition on Release of Glutamate and Dopamine in Prefrontal Cortex and Nucleus Accumbens in Phencyclidine Model of Schizophrenia. Journal of Biological Chemistry 2012, 287 (26), 21773-21782.

19. Elsworth, J. D.; Morrow, B. A.; Hajszan, T.; Leranth, C.; Roth, R. H., Phencyclidine-induced Loss of Asymmetric Spine Synapses in Rodent Prefrontal Cortex is Reversed by Acute and Chronic Treatment with Olanzapine. Neuropsychopharmacology 2011, 36 (10), 2054-2061.

20. Finnerty, N. J.; Bolger, F. B.; Palsson, E.; Lowry, J. P., An Investigation of Hypofrontality in an Animal Model of Schizophrenia Using Real-Time Microelectrochemical Sensors for Glucose, Oxygen, and Nitric Oxide. Acs Chemical Neuroscience 2013, 4 (5), 825-831.

21. Palmowski, P.; Rogowska-Wrzesinska, A.; Williamson, J.; Beck, H. C.; Mikkelsen, J. D.; Hansen, H. H.; Jensen, O. N., Acute Phencyclidine Treatment Induces Extensive and Distinct Protein Phosphorylation in Rat Frontal Cortex. Journal of Proteome Research 2014, 13 (3), 1578-1592.

22. Ernst, A.; Ma, D.; Garcia-Perez, I.; Tsang, T. M.; Kluge, W.; Schwarz, E.; Guest, P. C.; Holmes, E.; Sarnyai, Z.; Bahn, S., Molecular Validation of the Acute Phencyclidine Rat Model for Schizophrenia: Identification of Translational Changes in Energy Metabolism and Neurotransmission. Journal of Proteome Research 2012, 11 (7), 3704-3714. 
23. (a) Cosgrove, J.; Newell, T. G., Recovery of neuropsychological functions during reduction in use of phencyclidine. J Clin Psychol 1991, 47 (1), 159-69; (b) Pearlson, G. D., Psychiatric and medical syndromes associated with phencyclidine (PCP) abuse. Johns Hopkins Med J 1981, 148 (1), 25-33; (c) Rainey, J. M., Jr.; Crowder, M. K., Prolonged psychosis attributed to phencyclidine: report of three cases. Am J Psychiatry 1975, 132 (10), 1076-8.

24. Wesseling, H.; Chan, M. K.; Tsang, T. M.; Ernst, A.; Peters, F.; Guest, P. C.; Holmes, E.; Bahn, S., A Combined Metabonomic and Proteomic Approach Identifies Frontal Cortex Changes in a Chronic Phencyclidine Rat Model in Relation to Human Schizophrenia Brain Pathology. Neuropsychopharmacology 2013, 38 (12), 2532-2544.

25. Wesseling, H.; Rahmoune, H.; Tricklebank, M.; Guest, P. C.; Bahn, S., A Targeted Multiplexed Proteomic Investigation Identifies Ketamine-Induced Changes in Immune Markers in Rat Serum and Expression Changes in Protein Kinases/Phosphatases in Rat Brain. J Proteome Res.

26. Hackstadt, A. J.; Hess, A. M., Filtering for increased power for microarray data analysis. Bmc Bioinformatics 2009, 10.

27. Schwender, H., Siggenes: Multiple testing using SAM and Efron's empirical Bayes approaches. $R$ package version 1.38.0 2012.

28. Benjamini, Y.; Hochberg, Y., Controlling the False Discovery Rate - a Practical and Powerful Approach to Multiple Testing. Journal of the Royal Statistical Society Series B-Methodological 1995, $57(1), 289-300$.

29. Want, E. J.; Masson, P.; Michopoulos, F.; Wilson, I. D.; Theodoridis, G.; Plumb, R. S.; Shockcor, J.; Loftus, N.; Holmes, E.; Nicholson, J. K., Global metabolic profiling of animal and human tissues via UPLC-MS. Nature Protocols 2013, 8 (1), 17-32.

30. (a) Smith, C. A.; Want, E. J.; O'Maille, G.; Abagyan, R.; Siuzdak, G., XCMS: Processing mass spectrometry data for metabolite profiling using Nonlinear peak alignment, matching, and identification. Analytical Chemistry 2006, 78 (3), 779-787; (b) Tautenhahn, R.; Bottcher, C.; Neumann, S., Highly sensitive feature detection for high resolution LC/MS. Bmc Bioinformatics 2008, 9; (c) Smith, C. A.; Want, E. J.; O'Maille, G.; Abagyan, R.; Siuzdak, G., XCMS: processing mass spectrometry data for metabolite profiling using nonlinear peak alignment, matching, and identification. Anal Chem 2006, 78 (3), 779-87.

31. (a) Hackstadt, A. J.; Hess, A. M., Filtering for increased power for microarray data analysis. BMC Bioinformatics 2009, 10, 11; (b) Bourgon, R.; Gentleman, R.; Huber, W., Independent filtering increases detection power for high-throughput experiments. Proceedings of the National Academy of Sciences of the United States of America 2010, 107 (21), 9546-9551.

32. (a) Martins-de-Souza, D.; Menezes de Oliveira, B.; dos Santos Farias, A.; Horiuchi, R. S.; Crepaldi Domingues, C.; de Paula, E.; Marangoni, S.; Gattaz, W. F.; Dias-Neto, E.; Camillo Novello, J., The use of ASB-14 in combination with CHAPS is the best for solubilization of human brain proteins for two-dimensional gel electrophoresis. Brief Funct Genomic Proteomic 2007, 6 (1), 70-5; (b) Wesseling, H.; Guest, P. C.; Lee, C. M.; Wong, E. H. F.; Rahmoune, H.; Bahn, S., Integrative proteomic analysis of the NMDA NR1 knockdown mouse model reveals effects on central and peripheral pathways associated with schizophrenia and autism spectrum disorders. Molecular Autism $2014,5$.

33. Li, G. Z.; Vissers, J. P.; Silva, J. C.; Golick, D.; Gorenstein, M. V.; Geromanos, S. J., Database searching and accounting of multiplexed precursor and product ion spectra from the data independent analysis of simple and complex peptide mixtures. Proteomics 2009, 9 (6), 1696-719.

34. (a) Lu, P.; Vogel, C.; Wang, R.; Yao, X.; Marcotte, E. M., Absolute protein expression profiling estimates the relative contributions of transcriptional and translational regulation. Nature Biotechnology 2007, 25 (1), 117-124; (b) Yang, X.; Levin, Y.; Rahmoune, H.; Ma, D.; Schoffmann, S.; Umrania, Y.; Guest, P. C.; Bahn, S., Comprehensive two-dimensional liquid chromatography mass spectrometric profiling of the rat hippocampal proteome. Proteomics 2011, 11 (3), 501-505; (c) Krishnamurthy, D.; Levin, Y.; Harris, L. W.; Umrania, Y.; Bahn, S.; Guest, P. C., Analysis of the human pituitary proteome by data independent label-free liquid chromatography tandem mass spectrometry. Proteomics 2011, 11 (3), 495-500; (d) Ralhan, R.; Masui, O.; DeSouza, L. V.; Matta, A.; 
Macha, M.; Siu, K. W. M., Identification of proteins secreted by head and neck cancer cell lines using LC-MS/MS: Strategy for discovery of candidate serological biomarkers. Proteomics 2011, 11 (12), 2363-2376.

35. Clough, T.; Thaminy, S.; Ragg, S.; Aebersold, R.; Vitek, O., Statistical protein quantification and significance analysis in label-free LC-MS experiments with complex designs. Bmc Bioinformatics 2012, 13.

36. Wesseling, H.; Gottschalk, M. G.; Bahn, S., Targeted multiplexed selected reaction monitoring analysis evaluates protein expression changes of molecular risk factors for major psychiatric disorders. Int I Neuropsychopharmacol 18 (1).

37. Picotti, P.; Rinner, O.; Stallmach, R.; Dautel, F.; Farrah, T.; Domon, B.; Wenschuh, H.; Aebersold, R., High-throughput generation of selected reaction-monitoring assays for proteins and proteomes. Nature Methods 2010, 7 (1), 43-U5.

38. Lange, V.; Malmstrom, J. A.; Didion, J.; King, N. L.; Johansson, B. P.; Schafer, J.; Rameseder, J.; Wong, C. H.; Deutsch, E. W.; Brusniak, M. Y.; Buhlmann, P.; Bjorck, L.; Domon, B.; Aebersold, R., Targeted quantitative analysis of Streptococcus pyogenes virulence factors by multiple reaction monitoring. Mol Cell Proteomics 2008, 7 (8), 1489-500.

39. Farrah, T.; Deutsch, E. W.; Omenn, G. S.; Campbell, D. S.; Sun, Z.; Bletz, J. A.; Mallick, P.; Katz, J. E.; Malmstrom, J.; Ossola, R.; Watts, J. D.; Lin, B. A. Y.; Zhang, H.; Moritz, R. L.; Aebersold, R., A High-Confidence Human Plasma Proteome Reference Set with Estimated Concentrations in PeptideAtlas. Molecular \& Cellular Proteomics 2011, 10 (9).

40. MacLean, B.; Tomazela, D. M.; Shulman, N.; Chambers, M.; Finney, G. L.; Frewen, B.; Kern, R.; Tabb, D. L.; Liebler, D. C.; MacCoss, M. J., Skyline: an open source document editor for creating and analyzing targeted proteomics experiments. Bioinformatics 2010, 26 (7), 966-968.

41. Oberg, A. L.; Vitek, O., Statistical Design of Quantitative Mass Spectrometry-Based Proteomic Experiments. Journal of Proteome Research 2009, 8 (5), 2144-2156.

42. Chang, C. Y.; Picotti, P.; Huttenhain, R.; Heinzelmann-Schwarz, V.; Jovanovic, M.; Aebersold, R.; Vitek, O., Protein Significance Analysis in Selected Reaction Monitoring (SRM) Measurements. Molecular \& Cellular Proteomics 2012, 11 (4).

43. Surinova, S.; Huttenhain, R.; Chang, C. Y.; Espona, L.; Vitek, O.; Aebersold, R., Automated selected reaction monitoring data analysis workflow for large-scale targeted proteomic studies. Nature Protocols 2013, 8 (8), 1602-1619.

44. Alexa, A.; Rahnenfuhrer, J.; Lengauer, T., Improved scoring of functional groups from gene expression data by decorrelating GO graph structure. Bioinformatics 2006, 22 (13), 1600-7.

45. Ashburner, M.; Ball, C. A.; Blake, J. A.; Botstein, D.; Butler, H.; Cherry, J. M.; Davis, A. P.; Dolinski, K.; Dwight, S. S.; Eppig, J. T.; Harris, M. A.; Hill, D. P.; Issel-Tarver, L.; Kasarskis, A.; Lewis, S.; Matese, J. C.; Richardson, J. E.; Ringwald, M.; Rubin, G. M.; Sherlock, G.; Consortium, G. O., Gene Ontology: tool for the unification of biology. Nature Genetics 2000, 25 (1), 25-29.

46. Sturn, A.; Quackenbush, J.; Trajanoski, Z., Genesis: cluster analysis of microarray data. Bioinformatics 2002, 18 (1), 207-8.

47. (a) Sarnyai, Z.; Alsaif, M.; Bohn, S.; Ernst, A.; Guest, P. C.; Hradetzky, E.; Kluge, W.; Stelzhammer, V.; Wesseling, H., Behavioral and Molecular Biomarkers in Translational Animal Models for Neuropsychiatric Disorders. Biomarkers of Neurological and Psychiatric Disease 2011, 101, 203-238; (b) Sarnyai, Z.; Jashar, C.; Olivier, B., Modeling combined schizophrenia-related behavioral and metabolic phenotypes in rodents. Behavioural Brain Research 2015, 276, 130-142.

48. Simma, N.; Bose, T.; Kahlfuss, S.; Mankiewicz, J.; Lowinus, T.; Luhder, F.; Schuler, T.; Schraven, B.; Heine, M.; Bommhardt, U., NMDA-receptor antagonists block B-cell function but foster IL-10 production in BCR/CD40-activated B cells. Cell Commun Signal 2014, 12 (1), 75.

49. Upthegrove, R.; Manzanares-Teson, N.; Barnes, N. M., Cytokine function in medication-naive first episode psychosis: A systematic review and meta-analysis. Schizophrenia Research 2014, 155 (13), 101-108. 
50. Tourjman, V.; Kouassi, E.; Koue, M. E.; Rocchetti, M.; Fortin-Fournier, S.; Fusar-Poli, P.; Potvin, S., Antipsychotics' effects on blood levels of cytokines in schizophrenia: A meta-analysis. Schizophrenia Research 2013, 151 (1-3), 43-47.

51. Asevedo, E.; Rizzo, L. B.; Gadelha, A.; Mansur, R. B.; Ota, V. K.; Berberian, A. A.; Scarpato, B. S.; Teixeira, A. L.; Bressan, R. A.; Brietzke, E., Peripheral interleukin-2 level is associated with negative symptoms and cognitive performance in schizophrenia. Physiology \& Behavior 2014, 129, 194-198.

52. Paul-Samojedny, M.; Owczarek, A.; Kowalczyk, M.; Suchanek, R.; Palacz, M.; Kucia, K.; FilaDanilow, A.; Borkowska, P.; Kowalski, J., Association of Interleukin 2 (IL-2), Interleukin 6 (IL-6), and TNF-alpha (TNF alpha) Gene Polymorphisms With Paranoid Schizophrenia in a Polish Population. Journal of Neuropsychiatry and Clinical Neurosciences 2013, 25 (1), 72-82.

53. Stuart, M. J.; Baune, B. T., Chemokines and chemokine receptors in mood disorders, schizophrenia, and cognitive impairment: A systematic review of biomarker studies. Neuroscience and Biobehavioral Reviews 2014, 42, 93-115.

54. Elomaa, A. P.; Niskanen, L.; Herzig, K. H.; Viinamaki, H.; Hintikka, J.; Koivumaa-Honkanen, H.; Honkalampi, K.; Valkonen-Korhonen, M.; Harvima, I. T.; Lehto, S. M., Elevated levels of serum IL-5 are associated with an increased likelihood of major depressive disorder. Bmc Psychiatry 2012, 12.

55. Fumagalli, F.; Molteni, R.; Bedogni, F.; Gennarelli, M.; Perez, J.; Racagni, G.; Riva, M. A., Quetiapine regulates FGF-2 and BDNF expression in the hippocampus of animals treated with MK801. Neuroreport 2004, 15 (13), 2109-2112.

56. Takebayashi, M.; Hashimoto, R.; Hisaoka, K.; Tsuchioka, M.; Kunugi, H., Plasma levels of vascular endothelial growth factor and fibroblast growth factor 2 in patients with major depressive disorders. Journal of Neural Transmission 2010, 117 (9), 1119-1122.

57. Gaughran, F.; Payne, J.; Sedgwick, P. M.; Cotter, D.; Berry, M., Hippocampal FGF-2 and FGFR1 mRNA expression in major depression, schizophrenia and bipolar disorder. Brain Res Bull 2006, 70 (3), 221-7.

58. Deguchi, Y.; Okutsu, H.; Okura, T.; Yamada, S.; Kimura, R.; Yuge, T.; Furukawa, A.; Morimoto, K.; Tachikawa, M.; Ohtsuki, S.; Hosoya, K.; Terasaki, T., Internalization of basic fibroblast growth factor at the mouse blood-brain barrier involves perlecan, a heparan sulfate proteoglycan. Journal of Neurochemistry 2002, 83 (2), 381-389.

59. (a) Kuhn, H. G.; Winkler, J.; Kempermann, G.; Thal, L. J.; Gage, F. H., Epidermal growth factor and fibroblast growth factor-2 have different effects on neural progenitors in the adult rat brain. Journal of Neuroscience 1997, 17 (15), 5820-5829; (b) Wagner, J. P.; Black, I. B.; DiCicco-Bloom, E., Stimulation of neonatal and adult brain neurogenesis by subcutaneous injection of basic fibroblast growth factor. Journal of Neuroscience 1999, 19 (14), 6006-6016; (c) Werner, S.; Unsicker, K.; von Bohlen und Halbach, O., Fibroblast Growth Factor-2 Deficiency Causes Defects in Adult Hippocampal Neurogenesis, Which Are Not Rescued by Exogenous Fibroblast Growth Factor-2. Journal of Neuroscience Research 2011, 89 (10), 1605-1617.

60. Musaelyan, K.; Egeland, M.; Fernandes, C.; Pariante, C. M.; Zunszain, P. A.; Thuret, S., Modulation of Adult Hippocampal Neurogenesis by Early-Life Environmental Challenges Triggering Immune Activation. Neural Plasticity 2014.

61. (a) Schulz, T. W.; Nakagawa, T.; Licznerski, P.; Pawlak, V.; Kolleker, A.; Rozov, A.; Kim, J.; Dittgen, T.; Kohr, G.; Sheng, M.; Seeburg, P. H.; Osten, P., Actin/alpha-actinin-dependent transport of AMPA receptors in dendritic spines: Role of the PDZ-LIM protein RIL. Journal of Neuroscience 2004, 24 (39), 8584-8594; (b) Wyszynski, M.; Lin, J.; Rao, A.; Nigh, E.; Beggs, A. H.; Craig, A. M.; Sheng, M., Competitive binding of alpha-actinin and calmodulin to the NMDA receptor. Nature 1997, 385 (6615), 439-442.

62. Weinberger, D. R.; Berman, K. F.; Zec, R. F., Physiologic dysfunction of dorsolateral prefrontal cortex in schizophrenia. I. Regional cerebral blood flow evidence. Arch Gen Psychiatry 1986, 43 (2), 114-24.

63. Heckers, S.; Konradi, C., Hippocampal neurons in schizophrenia. J Neural Transm 2002, 109 (5-6), 891-905. 
64. Hradetzky, E.; Sanderson, T. M.; Tsang, T. M.; Sherwood, J. L.; Fitzjohn, S. M.; Lakics, V.; Malik, N.; Schoeffmann, S.; O'Neill, M. J.; Cheng, T. M. K.; Harris, L. W.; Rahmoune, H.; Guest, P. C.; Sher, E.; Collingridge, G. L.; Holmes, E.; Tricklebank, M. D.; Bahn, S., The Methylazoxymethanol Acetate (MAM-E17) Rat Model: Molecular and Functional Effects in the Hippocampus. Neuropsychopharmacology 2012, 37 (2), 364-377.

65. (a) Lei, G.; Xia, Y.; Johnson, K. M., The role of Akt-GSK-3beta signaling and synaptic strength in phencyclidine-induced neurodegeneration. Neuropsychopharmacology 2008, 33 (6), 1343-53; (b) Olney, J. W.; Wozniak, D. F.; Jevtovic-Todorovic, V.; Farber, N. B.; Bittigau, P.; Ikonomidou, C., Druginduced apoptotic neurodegeneration in the developing brain. Brain Pathol 2002, 12 (4), 488-98.

66. (a) Manns, J. R.; Hopkins, R. O.; Squire, L. R., Semantic memory and the human hippocampus. Neuron 2003, 38 (1), 127-133; (b) Zolamorgan, S.; Squire, L. R., Neuroanatomy of Memory. Annual Review of Neuroscience 1993, 16, 547-563.

67. Harrison, P. J.; Law, A. J.; Eastwood, S. L., Glutamate receptors and transporters in the hippocampus in schizophrenia. Ann N Y Acad Sci 2003, 1003, 94-101.

68. (a) Kreeger, J. S.; Yukhananov, R.; Larson, A. A., Increased N-methyl-D-aspartate (NMDA) activity in the mouse spinal cord following morphine does not mediate opioid withdrawal. Brain Res 1994, 663 (1), 101-6; (b) Sharp, J. W., Phencyclidine (PCP) acts at sigma sites to induce c-fos gene expression. Brain Res 1997, 758 (1-2), 51-8; (c) Ingram, S. L., Association of Mu-opioid and NMDA Receptors in the Periaqueductal Gray: What Does it Mean for Pain Control? Neuropsychopharmacology 2012, 37 (2), 315-316; (d) Herman, B. H.; Vocci, F.; Bridge, P., The Effects of Nmda Receptor Antagonists and Nitric-Oxide Synthase Inhibitors on Opioid Tolerance and Withdrawal - Medication Development Issues for Opiate Addiction. Neuropsychopharmacology 1995, 13 (4), 269-293.

69. (a) Lisman, J. E.; Coyle, J. T.; Green, R. W.; Javitt, D. C.; Benes, F. M.; Heckers, S.; Grace, A. A., Circuit-based framework for understanding neurotransmitter and risk gene interactions in schizophrenia. Trends Neurosci 2008, 31 (5), 234-42; (b) Coyle, J. T., The GABA-glutamate connection in schizophrenia: which is the proximate cause? Biochem Pharmacol 2004, 68 (8), 1507-14.

70. Belforte, J. E.; Zsiros, V.; Sklar, E. R.; Jiang, Z. H.; Yu, G.; Li, Y. Q.; Quinlan, E. M.; Nakazawa, K., Postnatal NMDA receptor ablation in corticolimbic interneurons confers schizophrenia-like phenotypes. Nature Neuroscience 2010, 13 (1), 76-U240.

71. Valko, M.; Leibfritz, D.; Moncol, J.; Cronin, M. T.; Mazur, M.; Telser, J., Free radicals and antioxidants in normal physiological functions and human disease. Int J Biochem Cell Biol 2007, 39 (1), 44-84.

72. Rajasekaran, A.; Venkatasubramanian, G.; Berk, M.; Debnath, M., Mitochondrial dysfunction in schizophrenia: pathways, mechanisms and implications. Neurosci Biobehav Rev 2015, 48, 10-21.

73. Millo, S.; Charibit.A, Effect of Phencyclidine on Oxygen-Consumption of Rat-Brain Mitochondria in-Vitro and in-Vivo. Biochemical Pharmacology 1973, 22 (13), 1661-1665.

74. Flatow, J.; Buckley, P.; Miller, B. J., Meta-Analysis of Oxidative Stress in Schizophrenia. Biological Psychiatry 2013, 74 (6), 400-409.

75. Steullet, P.; Cabungcal, J. H.; Cuenod, M.; Do, K. Q., Fast oscillatory activity in the anterior cingulate cortex: dopaminergic modulation and effect of perineuronal net loss. Frontiers in Cellular Neuroscience 2014, 8. 
Figure 1. Overview of the proteomic and metabonomic profiling results. Volcano plots of group comparisons showing the adjusted significance values versus fold change distributions. Horizontal grey lines indicate the adjusted $\mathrm{p}$ value threshold of 0.05 , vertical grey dotted lines indicate a fold-change threshold of $10 \%$ (proteomics) and 50\% (metabonomics, shown for positive ion mode). Green dots represent down regulated proteins/metabolites, red dots represent up regulated protein/metabolites. Grey/black dots represent proteins/metabolites not meeting the threshold. (Neg.) = negative ion mode. (Pos.) = positive ion mode. Full information can be found in the supplementary information. $254 \times 190 \mathrm{~mm}(96 \times 96 \mathrm{DPI})$ 


\section{Figure 2}

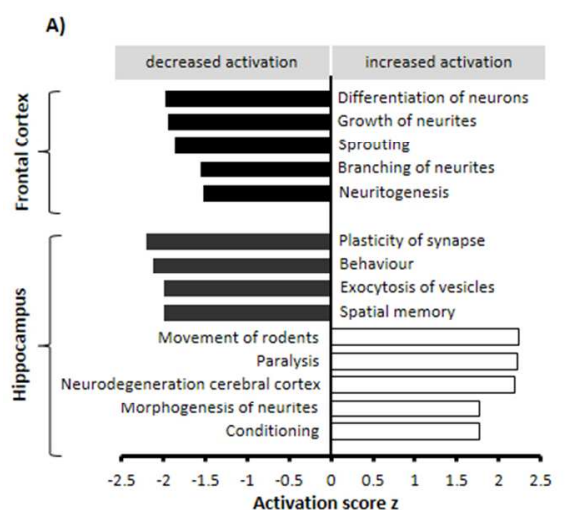

B)
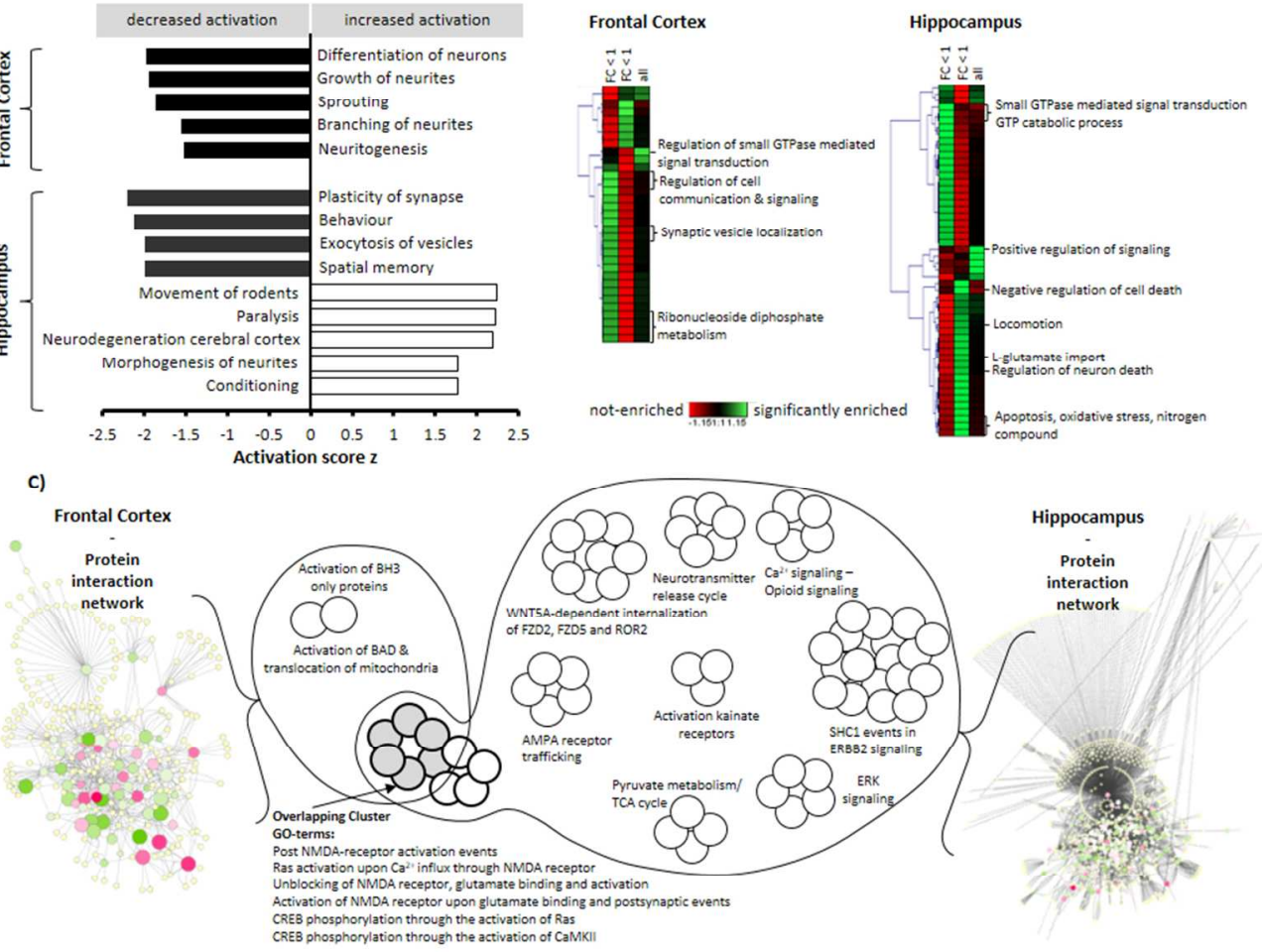

Computational Pathway analysis of the CPCP-induced proteomic alterations in frontal cortex and hippocampus brain tissue. A) Ingenuity Pathway Analysis (IPA) showing significantly decreased (black bars, minus sign) and increased (white bars, plus sign) biological functions in CPCP rat brain regions. Functions $(p<0.05)$ are shown with an activation score $(z$-score) $>1$ (increased activation) or $<-1$ (decreased activation). B) Cytoscape generated interaction clusters based on the altered proteins $(p<0.05)$ in the frontal cortex and hippocampus. Protein interaction networks were created using the IMEx databases and ClueGO was applied to identify clusters within. Overlapping GO-terms amongst the clusters are indicated by grey shading. Circles represent different GO-terms within the cluster. C) Functional enrichment analysis of significantly changed proteins in frontal cortex and hippocampus of the CPCP rat. Proteins were split into fold-change bins for separate analyses. Colour coded z-score transformed p-values indicate the significance of the enrichment for each bin as indicated. $254 \times 254 \mathrm{~mm}(96 \times 96 \mathrm{DPI})$ 


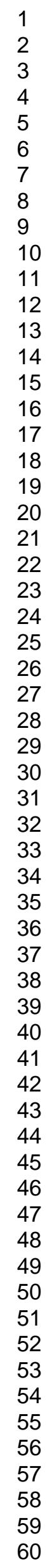

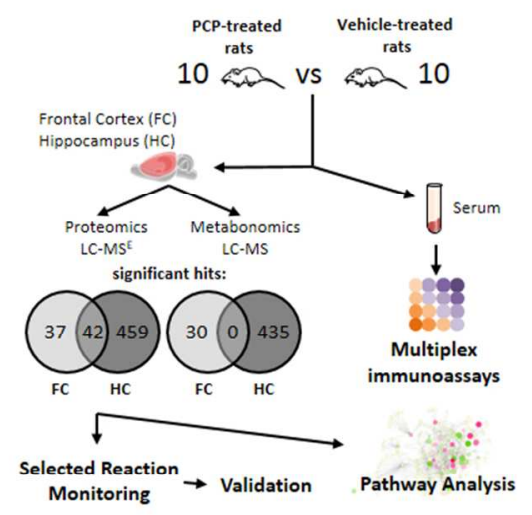

for TOC only $254 \times 190 \mathrm{~mm}(96 \times 96 \mathrm{DPI})$ 